Article

\title{
Electrodeposition of Mn-Co/Polypyrrole Nanocomposites: An Electrochemical and In Situ Soft-X-ray Microspectroscopic Investigation
}

\author{
Benedetto Bozzini ${ }^{1}{ }^{*}$, Patrizia Bocchetta ${ }^{1}$, George Kourousias ${ }^{2}$ and Alessandra Gianoncelli ${ }^{2}$ \\ 1 Dipartimento di Ingegneria dell'Innovazione, Università del Salento, via Monteroni, 73100 Lecce, Italy; \\ patrizia.bocchetta@unisalento.it \\ 2 Elettra-Sincrotrone Trieste S.C.p.A. strada statale 14 km 163.5 in Area Science Park, Basovizza, 34012 Trieste, \\ Italy; george.kourousias@elettra.eu (G.K.); alessandra.gianoncelli@elettra.eu (A.G.) \\ * Correspondence: benedetto.bozzini@unisalento.it; Tel.: +39-832-297-323
}

Academic Editor: Walter Remo Caseri

Received: 11 November 2016; Accepted: 23 December 2016; Published: 6 January 2017

\begin{abstract}
Understanding the lateral variations in the elemental and chemical state of constituents induced by electrochemical reactions at nanoscales is crucial for the advancement of electrochemical materials science. This requires in situ studies to provide observables that contribute to both modeling beyond the phenomenological level and exactly transducing the functionally relevant quantities. A range of X-ray coherent diffraction imaging (CDI) approaches have recently been proposed for imaging beyond the diffraction limit with potentially dramatic improvements in time resolution with chemical sensitivity. In this paper, we report a selection of ptychography results obtained in situ during the electrodeposition of a metal-polymer nanocomposite. Our selection includes dynamic imaging during electrochemically driven growth complemented with absorption and phase spectroscopy with high lateral resolution. We demonstrate the onset of morphological instability feature formation and correlate the chemical state of $\mathrm{Mn}$ with the local growth rate controlled by the current density distribution resulting from morphological evolution.
\end{abstract}

Keywords: manganese oxide; polypyrrole; nanocomposites; electrodeposition; coherent diffractive imaging; ptychography

\section{Introduction}

Manganese oxides are popular non-precious oxygen reduction reaction (ORR) catalysts for metal/air batteries [1] owing to their low cost, adequate electrochemical stability and good catalytic activity towards the decomposition of hydrogen peroxide, produced by the ORR $2 \mathrm{e}^{-}$pathway, typical for alkaline solutions [2-4]. The strong interest in $\mathrm{MnO}_{\mathrm{x}}$ as an electrode material is also related to its good catalytic activity toward the oxygen evolution reaction (OER) [5-8] that is required for rechargeable and/or reversible systems. Unfortunately, the ORR electrocatalytic activity of $\mathrm{MnO}_{\mathrm{x}}$ is generally inferior to that of platinum-based electrocatalysts: it exhibits higher overpotentials and it cannot follow the optimal four-electron pathway [9,10]; moreover, its electrochemical stability is not satisfactory. One of the approaches that have been proposed to improve the ORR electrocatalytic performance of manganese oxides, is based on the addition of metal ions, such as: $\mathrm{Ni}(\mathrm{II}), \mathrm{Ca}$ (II), $\mathrm{Mg}(\mathrm{II}), \mathrm{Bi}(\mathrm{III}), \mathrm{Cr}(\mathrm{III}), \mathrm{V}(\mathrm{V}), \mathrm{Mo}(\mathrm{IV}), \mathrm{La}(\mathrm{III}), \mathrm{Co}(\mathrm{II})$ [3,11-14]. The typical alloying effect is twofold: (i) a desirable increase in the half-wave potential, related to a better activity conferred by the transitional dopants; and (ii) the stabilisation of the intermediate $\mathrm{Mn}(\mathrm{III}) / \mathrm{Mn}(\mathrm{IV})$ phase that enhances the oxygen bond splitting, resulting in a favoured four-electron ORR pathway [3,15-18]. In particular, $\mathrm{Co}, \mathrm{Ni}$ and $\mathrm{Mg}$-doping of $\mathrm{MnO}_{\mathrm{x}}$ catalysts has been also reported to increase the durability of electrodes 
subjected to accelerated ORR ageing $[10,15,19-23]$. Among literature, transition metal additions to manganese oxides, binary $\mathrm{Mn}-\mathrm{Co}-\mathrm{O}_{\mathrm{x}}$ spinels $[10,19,20,23]$ and $\mathrm{MnO}_{\mathrm{x}} / \mathrm{CoO}_{\mathrm{x}}$ mixtures $[21,22]$ have been the most extensively studied as ORR catalysts in alkaline solutions, because of their high catalytic activity and good corrosion stability with respect to the pure components. Notwithstanding their electrocatalytic appeal, the practical application of Mn-Co oxides is impaired by their poor electrical conductivity: nevertheless, high-conductivity materials can be fabricated by composite synthesis routes, e.g., by dispersing the metal oxide particles into a polypyrrole (PPy) matrix. The use of PPy for the fabrication of composite ORR electrocatalysts is attractive for the following reasons: (i) it is an excellent support for catalysts both in the form of metal oxides [24] and metallorganic complexes [25,26]; (ii) if appropriately treated, it can act as a source of nitrogen, which is believed to enhance the electrocatalytic activity by forming $\mathrm{Mn}$ - or Co-N centers; (iii) it exhibits a good electronic conductivity in the doped form; (iv) it is easy to synthesise by chemical [27] or electrochemical [28] routes. Cong at al. $[24,29]$ were the first to demonstrate the possibility of decreasing the ohmic drop of mixed oxide materials and to protect the catalytic sites against dissolution during ORR operation, by growing composite electrodes by alternating layers of PPy and $\mathrm{MnCu}$ or $\mathrm{NiCu}$ oxide spinel particles. These workers incorporated the oxide particles-that had been pre-synthesised by thermal decomposition-into electrodeposited PPy. As far as the Mn-Co/PPy system is concerned, a recent paper describes the incorporation of manganese cobaltite nanorods into PPy and investigates the ORR mechanism for these materials [30]. An alternative approach to the incorporation of pre-synthesised particles into electrodeposited PPy is to form both the oxide and the conducting polymer by a fully electrochemical route. This approach has been described for Co/PPy [31-33] and Mn/PPy [31,32,34-36]. In this paper, we extend this approach to the growth of mixed-oxide/PPy composites, in particular concentrating on an in situ dynamic description of the morphochemical development of the composite material during electrodeposition, based on complementary electrochemical and soft- $X$ ray absorption and fluorescence microspectroscopies.

\section{Materials and Methods}

\subsection{Electrochemical Measurements}

The present section describes the chemicals and equipment employed in the electrochemical fabrication protocols and electroanalytical measurements. The electrodeposition bath used to prepare $\mathrm{Mn}-\mathrm{Co} / \mathrm{PPy}$ nanocomposites contains $0.1 \mathrm{M}$ pyrrole, $25 \mathrm{mM} \mathrm{MnCl} 2,25 \mathrm{mM} \mathrm{CoCl}$, $0.1 \mathrm{M}$ tetra-butyl-ammonium-perchlorate (TBAP) and $1 \% v / v \mathrm{H}_{2} \mathrm{O}$ (ultrapure water with a resistivity of $18.2 \mathrm{M} \Omega \cdot \mathrm{cm}$ ) dissolved in acetonitrile. The small amount of water increases the electropolymerisation rate and improves the mechanical properties, the adhesion and the conductivity of the polymer matrix [33,37]. The electrochemical syntheses were performed using a self-fabricated conventional three-electrode cell with a glassy carbon rod (diameter: $3 \mathrm{~mm}$ ) working electrode (WE) and a Pt wire spiral $\left(5 \mathrm{~cm}^{2}\right)$ as counter electrode (CE) and an aqueous silver/silver chloride $(\mathrm{Ag} / \mathrm{AgCl}$ (3M): $0.209 \mathrm{~V} / \mathrm{NHE}$ ) as reference electrode (RE), connected to the solution by a salt bridge. The liquid junction potential between aqueous and non-aqueous solution has been found to be negligible. All the potentials are benchmarked against the $\mathrm{Ag} / \mathrm{AgCl}$ scale.

The electrochemical measurements were performed at room temperature using ParStat (Princeton Applied Research-Ametek, Berwin, PA, USA) and VersaSTAT potentiostats (Princeton Applied Research-Ametek, Berwin, PA, USA). Cyclic voltammetric (CV) analyses have been carried out at glassy carbon electrodes in the range $-2 \mathrm{~V} \div+1.2 \mathrm{~V}$ at a scan rate of $100 \mathrm{mV} \cdot \mathrm{s}^{-1}$. $\mathrm{N}_{2}$ (Rivoira, $5 \mathrm{~N}$ ) was bubbled for 20 min into the solution before the measurement and an $\mathrm{N}_{2}$ blanket was kept above the solution during electrochemistry. The WEs were polished mechanically to a mirror finish before each experiment and subsequently subjected to ultra-sonication in distilled water for $10 \mathrm{~min}$ and electrochemical oxidation of impurities in $0.5 \mathrm{M} \mathrm{H}_{2} \mathrm{SO}_{4}$ from 0 to $1.5 \mathrm{~V}$ at a scan rate of 
$100 \mathrm{mV} \cdot \mathrm{s}^{-1}$, as recommended in [31]. The counter electrode was cleaned by immersion in concentrated $\mathrm{HNO}_{3}$ to remove metal impurities and by annealing in a butane flame to eliminate organic residues.

$\mathrm{Mn}-\mathrm{Co} / \mathrm{PPy}$ nanocomposite electrocatalyst were synthesised by modifying the step-pulsed potential procedure recently adopted for Co/PPy electrodeposition [31,33,37], involving suitable repetitions of the cycle detailed below. The potential values were selected according to the cyclic voltammetric results discussed in Section 3.1.1. This cycle is designed in order to grow a composite consisting of two constituents that are formed anodically (PPy, Mn more oxidised that $\left.\mathrm{Mn}^{2+}\right)$ and cathodically $\left(\mathrm{Co}^{\circ}, \mathrm{Mn}^{\circ}\right.$ and /or precipitated $\mathrm{Co}^{2+}$ - and $\mathrm{Mn}^{2+}$-containing species). The potential program is optimised in view of avoiding large monomer concentration gradients at the electrode-electrolyte interface during electropolymerisation and to minimise the stripping of metal particles during the anodic pulses. The initial step $(0 \mathrm{~V})$ does not lead to faradaic reactions, but it is required to relax the compositional double layer. After this relaxation step, a layer of PPy is electrodeposited during the first anodic pulse $(1.2 \mathrm{~V})$. During the subsequent cathodic pulse $(-1.8 \mathrm{~V})$, reduced $\mathrm{Co}$ and $\mathrm{Mn}$ or precipitated $\mathrm{Co}^{2+}$ and $\mathrm{Mn}^{2+}$ species can be incorporated into PPy. In the final anodic step of each cycle (1.2 V), another layer of-possibly Mn-doped-PPy is deposited. Some reference $\mathrm{Mn}-\mathrm{Co} / \mathrm{PPy}$ films have been grown directly onto functionalised TEM (Transmission Electron Microscopy)-grid electrodes, as described in [37].

The electrocatalytic activity of Mn-Co/PPy samples towards ORR was evaluated by linear sweep voltammetric (LSV) measurements in $\mathrm{O}_{2}$-saturated (SIAD 6.0) $0.1 \mathrm{M} \mathrm{KOH}$ electrolyte under quasi-steady-state conditions $\left(5 \mathrm{mV} \cdot \mathrm{s}^{-1}\right)$ at different Rotating Disk Electrode (RDE) rotation speeds. A glassy carbon (GC) electrode (AMEL via S. G.B. De La Salle 4, 20132 Milano, Italy) with Mn-Co/PPy electrodeposit (for details on electrodeposition see Section 3.1) was mounted in a RDE (Parstat Model 2273, Princeton Applied Research-Ametek, Berwin, PA, USA). For reference purposes, the same electrochemical experiments were duplicated with solutions that had been de-oxygenated by $\mathrm{N}_{2}$ saturation. $\mathrm{O}_{2}$ was bubbled for 20 min into the solution before the measurements and an $\mathrm{O}_{2}$ blanket was maintained above the electrolyte during voltammetry. The ORR Levich slopes have been evaluated by using current-voltage curves from which the $\mathrm{N}_{2}$-background had been subtracted. The current densities are referred to the geometric area.

\subsection{Soft-X-ray Fluorescence and Absorption Microspectroscopies}

Soft X-ray fluorescence (XRF) elemental mapping was performed at the TwinMic beamline of Elettra synchrotron facility (Trieste, Italy) $[38,39]$. The photon beam was focused to a microprobe using zone plate optics and the imaging measurements were performed by simultaneous detection of transmitted and emitted (fluorescence) photons raster-scanning the sample with respect to the microprobe. The transmitted photons were detected using a fast readout CCD (Charge Coupled Device) camera (Andor Technology Ltd., Belfast, Northern Ireland), generating absorption and phase contrast images [40,41], whereas the emitted fluorescence signal was collected by means of 8 Silicon Drift Detectors (SDDs) located in an annular geometry in front of the specimen [42,43]. XAS (X-ray Absorption Spectroscopy) spectroscopy can also be applied on specific points of interest by using a photodiode located downstream the specimen. For the specific experiment shown in this paper XRF mapping was combined with absorption imaging. Photon energies in the ranges: $635-648 \mathrm{eV}$ and 764-790 eV were chosen to set the best excitation conditions for $\mathrm{Mn}$ and $\mathrm{Co}$ and well as to measure stacks of absorption images, as detailed in Section 3.3.3. The XRF elemental mapping was performed at $920 \mathrm{eV}$ in order to excite both Co and Mn: The responses of each of the 8 SDDs was recorded and summed together. The deconvolution of the fluorescence spectrum for each pixel was performed with the PyMCA software package [44], by using the Hypermet algorithm and linear baseline subtraction. Final data processing was carried out by Matlab (Version 6.5.0, The MathWorks Inc., Natick, MA, USA). The L emission lines of $\mathrm{Mn}(637.4 \mathrm{eV})$ and $\mathrm{Co}(797.0 \mathrm{eV})$, and the elastic scattering peak were monitored along the scanned area. The post size of the beam was chosen between $1.5 \mu \mathrm{m}$ and 
$250 \mathrm{~nm}$ according to the size of the feature of interests. It is worth emphasizing that, under the operating conditions adopted for this study, we did not assess any measurable radiation damage effect.

\section{Results and Discussion}

\subsection{Electrodeposition of $\mathrm{Mn}$-Co/PPy Composites}

\subsubsection{Cyclic Voltammetric Study}

Figure 1 reports cyclic voltammograms (CV) corresponding to (A) pyrrole polymerization, (B) Mn-Co electrodeposition and (C) Mn-Co/PPy co-electrodeposition from the solutions detailed in Section 2.1.

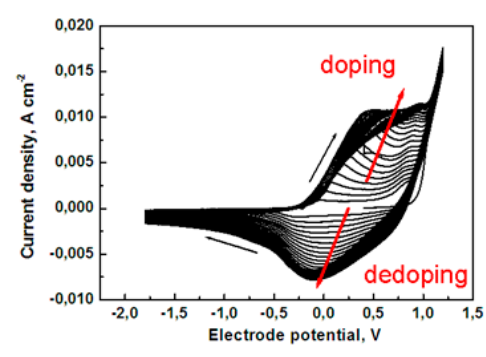

(A)

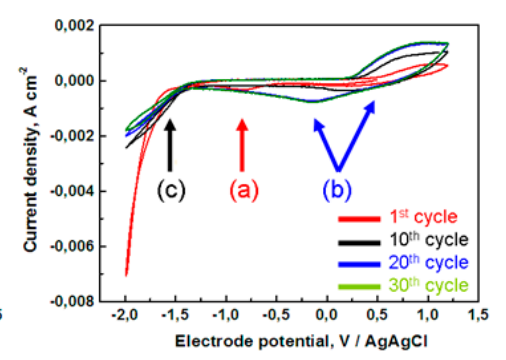

(B)

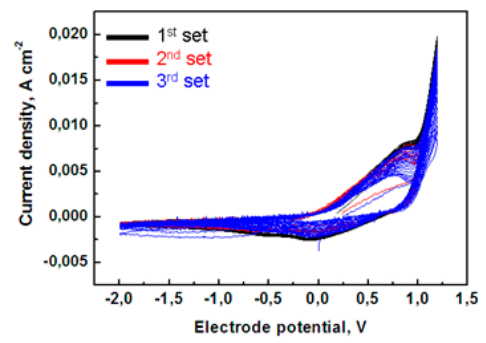

(C)

Figure 1. Cyclic voltammograms corresponding to: (A) pyrrole polymerisation; (B) codeposition of $\mathrm{Mn}$ and $\mathrm{Co} ;(\mathbf{C})$ codeposition of polypyrrole, $\mathrm{Mn}$ and $\mathrm{Co}$ (three independent replicated experiments). Glassy carbon (GC) electrode in contact with acetonitrile/water $1 \mathrm{vol} \%$ solutions containing $0.1 \mathrm{M}$ tetra-butyl-ammonium-perchlorate (TBAP) with added: (A) $0.1 \mathrm{M}$ pyrrole; (B) $0.025 \mathrm{M} \mathrm{MnCl}_{2}$ and $0.025 \mathrm{M} \mathrm{CoCl}_{2} ;$ (C) $0.1 \mathrm{M}$ pyrrole, $0.025 \mathrm{M} \mathrm{MnCl}_{2}$ and $0.025 \mathrm{M} \mathrm{CoCl}_{2}$. Scan rate $100 \mathrm{mV} \cdot \mathrm{s}^{-1}$.

\subsubsection{Electrodeposition of Pyrrole}

In Figure 1A, we plot the CVs for the electropolymerisation of pyrrole in $0.1 \mathrm{M}$ TBAP and $1 \% v / v \mathrm{H}_{2} \mathrm{O}$ de-aerated acetonitrile (ACN) solution. The first cycle follows the typical nucleation loop of conducting polymers [45] and the electrode process begins on the polymer-free GC surface at potentials higher than $0.9 \mathrm{~V}$, coherent with previous works [31,32]. In the successive cycles, two waves appear: The first one during the positive-going scan at $\sim 0-0.4 \mathrm{~V}$ and the second one during the cathodic scan at $\sim 0 \div-0.2 \mathrm{~V}$, corresponding, respectively, to the doping/un-doping processes of the PPy film with perchlorate anions $[32,46,47]$.

\subsubsection{Electrodeposition of Mn-Co}

In order to better understand the incorporation process of Mn and Co species into PPy during composite electrosynthesis, the electrochemical behaviour of mixed $\mathrm{MnCl}_{2} / \mathrm{CoCl}_{2}$ containing solution in absence of pyrrole has been investigated. The voltammetric analysis of the electrolytic solutions containing separately $\mathrm{CoCl}_{2}$ or $\mathrm{MnCl}_{2}$ can be found in previous works of ours: [32,34,36], respectively. Briefly, on the one hand, $\mathrm{CV}$ experiments conducted in $\mathrm{CoCl}_{2}$-containing solution [32] have shown the typical cathodic nucleation loop and anodic stripping peak of the metals. On the other hand, the electrochemical behavior of $\mathrm{MnCl}_{2}$-containing bath [34] was found to be more complex, as a result of different valence states for manganese that can prevail in the relevant electrochemical conditions used for our experiments. The CVs indicate that $\mathrm{Mn}$ (II) species oxidise mainly to $\mathrm{Mn}(\mathrm{III}, \mathrm{IV})$ oxide/hydroxide in the anodic scan and reduce to $\mathrm{Mn}(0)$ in the cathodic one. The electroreduction of $\mathrm{Mn}$ metal goes on through an irreversible process with a large difference (ca. $1 \mathrm{~V}$ ) between the $\mathrm{Mn}(\mathrm{II}) / \mathrm{Mn}(0)$ reduction peak and the corresponding anodic one, as observed in literature for $0.066 \mathrm{M} \mathrm{MnCl}_{2}$ /dimethyl formamide solution on Pt [48]. In our solution containing water, electrodeposited Mn metal is not thermodynamically stable and undergoes chemical oxidation by 
$\mathrm{H}_{2} \mathrm{O}$ producing $\mathrm{Mn}^{2+}$ (low $\mathrm{pH}$ ) or $\mathrm{Mn}(\mathrm{OH})_{2} / \mathrm{HMnO}_{2}{ }^{-}$(high $\mathrm{pH}$ ) [49]. This is confirmed by soft X-ray absorption spectroscopy of Mn/PPy samples, that have shown that Mn is present only in oxidised valence states: (II, III, IV) [34].

Figure $1 \mathrm{~B}$ reports the $\mathrm{CV}$ s recorded in the range $+1.2--2 \mathrm{~V}$ with solutions containing both $\mathrm{MnCl}_{2}$ and $\mathrm{CoCl}_{2}$ as the electroactive species. In the first cycle, one can notice a cathodic peak (1th cycle, peak (a)), that can be attributed to the reduction of the Co(II) complex present in the solution to $\mathrm{Co}(0)$, and the absence of a correspondent stripping wave: It is worth noting that such a stripping peak is recorded at $-0.05 \mathrm{~V}$ when only $\mathrm{CoCl}_{2}$ is present in the solution ([32] and references therein contained).

The irreversibility of the Co reduction peak is probably related to the fact that Co becomes covered by $\mathrm{Mn}(0)$ and / or by $\mathrm{Mn} / \mathrm{Co}$ oxyhydroxide electroreduced or electroprecipitation in the high-cathodic range of the CVs [50,51]. In fact, the reduction of water $\left(2 \mathrm{H}_{2} \mathrm{O}+2 \mathrm{e}^{-} \rightarrow \mathrm{H}_{2}+2 \mathrm{OH}^{-}\right)$-Producing a local increase of $\mathrm{pH}$-Is thermodynamically possible as the equilibrium standard potential in acetonitrile is reported to be $0 \mathrm{~V} / \mathrm{NHE}$ [52]. Both $\mathrm{Mn}$ (II) and $\mathrm{H}_{2} \mathrm{O}$ reduction occurs at about $-1.6 \mathrm{~V}$ in the first cycle and at more positive potentials $(-1.3 \mathrm{~V})$ in the subsequent ones (peak (c)). The gradual disappearance of the peak (a) (related to the formation of $\mathrm{Co}(\mathrm{II}) / \mathrm{Co}(0)$ ) with cycling, is coherent with the behaviour of the same bath containing only $\mathrm{CoCl}_{2}$, where the decrease of both $\mathrm{Co}(0)$ deposition and stripping waves were observed upon successive CV scans. Since this phenomenon has not been observed in aqueous solution containing the same electrolytes $\mathrm{CoCl}_{2}$ /TBAP [32], we can argue that the decisive role in the behaviour of Co plating/stripping CV waves is played by the coordination structures of $\mathrm{Co}$ complexes with acetonitrile.

In the anodic-going scan of the first potential cycle one can notice that a broad anodic wave appears at ca. $0.6 \mathrm{~V}$, followed by an apparent diffusion-controlled plateau. The onset potential of this wave is the same as that observed in baths containing only $\mathrm{MnCl}_{2}$, while the shape is significantly different. This behaviour can be ascribed to the possible anodic formation of mixed $\mathrm{Mn}-\mathrm{CoO}_{\mathrm{x}}$ or Co-doped $\mathrm{MnO}_{\mathbf{X}}[9,53]$, the $\mathrm{CV}$ behaviour of which can replace or partially overlap with (or kinetically modify) the typical one of $\mathrm{Mn}(\mathrm{III}, \mathrm{IV})$ oxides features, ascribed to the multi-step process illustrated in $[35,36,54]$.

The subsequent scans are very similar to those reported for electrolytes containing only $\mathrm{MnCl}_{2}$, with the exception that: (i) broader features are found when both metals salts and (ii) a new cathodic peak appears at $-0.55 \mathrm{~V}$ (peak (b)). As in the case of the pure Mn electrolyte, the anodic broad wave at ca. $0.6 \mathrm{~V}$ tends to grow in the anodic-going scans and in correspondence, a new cathodic peak located at $0.3 \mathrm{~V}$ appears after the 1 st cycle. This cathodic peak associated to $\mathrm{MnOOH} / \mathrm{Mn}$ (II) reduction in $\mathrm{MnCl}_{2}$ electrolyte, gradually shifts to more negative potentials (ca. $-0.55 \mathrm{~V}$ ) upon cycling, suggesting that the reduction process in $\mathrm{MnCl}_{2} / \mathrm{CoCl}_{2}$ bath involves the formation of mixed $\mathrm{Mn} / \mathrm{Co}$ oxide.

\subsubsection{Electrodeposition of PPy/Mn-Co}

In Figure 1C, we report three independent replicated CV curves obtained with the bath containing pyrrole, $\mathrm{MnCl}_{2}$ and $\mathrm{CoCl}_{2}$. The anodic electron-transfer processes corresponding to the formation of $\mathrm{Mn}(\mathrm{III}, \mathrm{IV})$ oxides and Mn-Co mixed oxides and the doping of PPy with perchlorate anions (Figure 1A) run in the same potential range. Moreover, it can be observed that the reduction processes of $\mathrm{Mn}(\mathrm{II})$ to $\mathrm{Mn}(0)$ and $\mathrm{OH}^{-}$generation occurring at ca. $-1.5 \mathrm{~V}$ in the absence of pyrrole (Figure $1 \mathrm{~B}$ ), are suppressed by the presence of the polymer, owing to the increase in ohmic drop caused by the un-doping process. At variance with the curves obtained in the solution free from $\mathrm{Mn}^{2+}$ and $\mathrm{Co}^{2+}$ (Figure 1A), the un-doping process $\left(\mathrm{ClO}_{4}{ }^{-}\right.$expulsion) of PPy is less evident with respect to the doping one, indicating that the incorporation of $\mathrm{Mn}$ species in the polymer during the anodic scan modifies its electronic structure. The modifications of the doping and un-doping curve revealed in Panel $\mathrm{C}$ can be interpreted by considering that $\mathrm{MnCl}_{2}$ and $\mathrm{CoCl}_{2}$ are able to form anionic complexes in $\mathrm{ACN}$ solvent and can thus be incorporated during the anodic electropolymerisation of pyrrole together with perchlorate anions. The incorporation of catalytic sites as counteranions by the polymerisation of pyrrole in a medium containing the anionic catalyst as the supporting electrolyte is a possible route to fabricate PPy-based catalytic electrodes [55-57]. Specifically, [58] demonstrated the incorporation 
of cobalt, iron and manganese porphyrin, iron and cobalt phthalocyanines, as well as cobalt(II) salts in PPy by doping with the relevant anions dissolved in the solution. In addition, Pt nanoparticles have been embedded into PPy films by doping with $\mathrm{PtCl}_{4}{ }^{2-}$ anions during the electropolymerisation and, subsequently, reduction of the anions within the polymer film [59]. Of course, CV analyses alone are not able to definitively establish the valence state of $\mathrm{Mn}$ and Co inside the polymer due to the complex electrochemistry of the bath and the presence of a multiplicity of oxidation and reduction processes (especially for Mn). For this reason, a multitechnique has been devised in this work, in order to elucidate the chemical distribution of the species inside the PPy matrix.

\subsubsection{Analysis of the Potentiostatic Chronoamperograms Recorded during Composite Synthesis}

\subsubsection{Anodic Potensiostatic Pulse}

Figure 2A shows the experimental current transients observed during the pulsed step potentiostatic synthesis of the Mn-Co/PPY samples. The shape of the curves with a well-defined current maximum $\left(t_{\mathrm{m}}, i_{\mathrm{m}}\right)$ is typical of the nucleation and growth of a new solid phase on an electrode [60-66] and can be studied with the nucleation and growth theory developed by Scharifker-Hills [67-72]. As discussed in Section 3.1.1, the possible anodic processes occurring at the applied electrode potential of $1.2 \mathrm{~V}$ are: (i) electropolymerisation of pyrrole; (ii) oxidation of the $\mathrm{Mn}(\mathrm{II})$ complexes in the bath and/or of the $\mathrm{Mn}(\mathrm{II}, \mathrm{III})$ and $\mathrm{Co}(0)$ species already incorporated in PPy and (iii) polymer doping with $\mathrm{ClO}_{4}{ }^{-}$and possibly with anionic complexes of $\mathrm{Mn}$ (II) and $\mathrm{Co}(\mathrm{II})$. These electrode reactions lead to the electrodeposition of a solid composite material made of PPy and $\mathrm{Mn} / \mathrm{Co}$ oxyhydroxides. All of these three kinds of electrode reactions are able to induce a nucleation and growth process at the electrochemical interface for: (i) PPy electropolymerisation [18,73-75] as well as (ii) anodic electrodeposition of $\mathrm{MnO}_{x}$ [76] and (iii) $\mathrm{CoO}_{x}$ [61]. Moreover, similar transient shapes have been demonstrated for PPy doping [77-79].
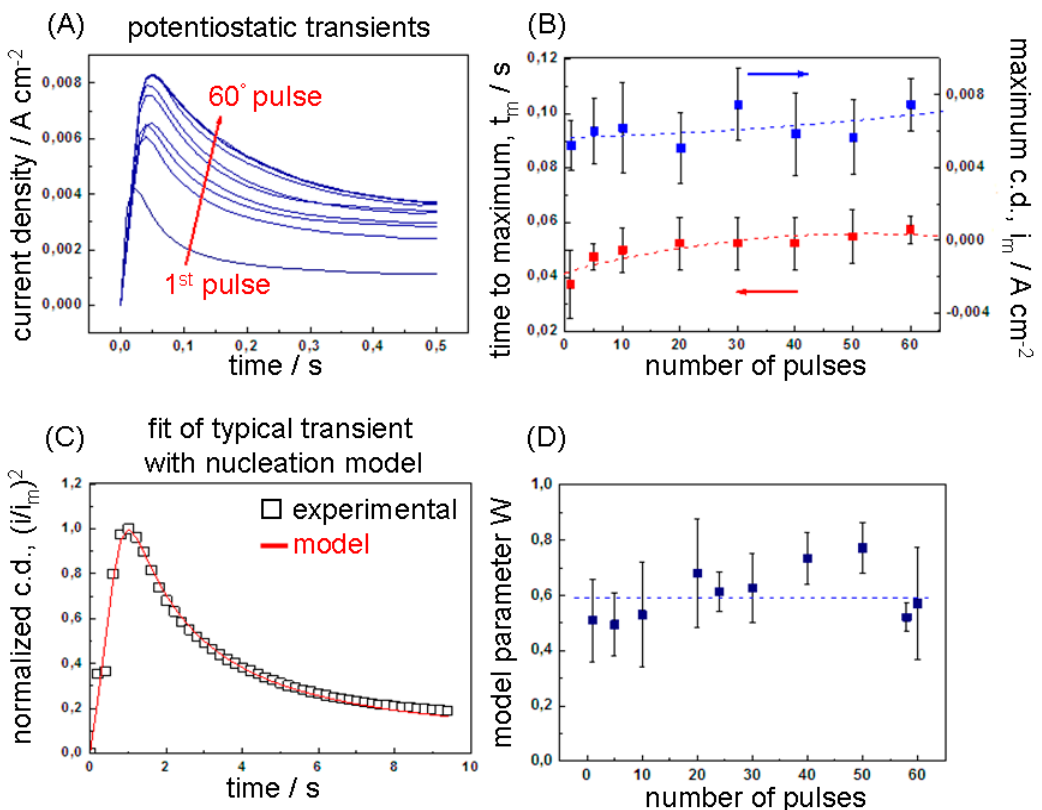

Figure 2. (A) Potentiostatic transients for the anodic growth of Mn-Co/PPy on a graphite electrode in contact with acetonitrile/water $1 \mathrm{vol} \%$ solutions containing $0.1 \mathrm{M}$ TBAP, $0.1 \mathrm{M}$ pyrrole, $0.025 \mathrm{M} \mathrm{MnCl}_{2}$ and $0.025 \mathrm{M} \mathrm{CoCl}_{2}$ at the applied potential of $1.2 \mathrm{~V}(\mathrm{Ag} / \mathrm{AgCl}) ;(\mathbf{B})$ Maximum current density $\left(i_{\mathrm{m}}\right)$ and the corresponding time $\left(t_{\mathrm{m}}\right)$ as a function of the number of the sequential pulses recorded during the electrosynthesis; (C) Dimensionless plot of a typical transient (the 45th one), compared with theoretical mixed nucleation curve [Mele 09]; (D) $W$ values obtained by best fitting of each anodic transient. The $i_{\mathrm{m}}, t_{\mathrm{m}}$ and $W$ values reported on the plot are averaged (the error bar is the standard deviation) on four independent experimental data sets. 
In Figure $2 \mathrm{~B}$, we report the maximum current density $\left(i_{\mathrm{m}}\right)$ and the corresponding time $\left(t_{\mathrm{m}}\right)$ as a function of the number of the sequential pulses recorded during the electrosynthesis. The $t_{\mathrm{m}}$ values ranging from 37 to $50 \mathrm{~ms}$ are in agreement with those reported for the electropolymerisation of pyrrole on GC [18] (0.06-0.15 s), highly oriented pyrolytic graphite (HOPG) [74,75] (0.1-0.2 s) and vitreous carbon [73] (0.026-0.15 s). It can be noticed that both parameters slightly increase with the pulse number (with more rapidity from the 1st to the 20th pulse). The increase of $t_{\mathrm{m}}$, associated to a decrease of the number of generated nuclei, can be explained by considering that the effective applied anodic potential slightly decreases with the progress of the pulses. It is worth noting that the rate at which the PPy oxidises (incorporates anions) at every anodic pulse is influenced by the preceding cathodic pulse, i.e., by the degree of compactness of the polymeric structure attained during the expulsion of anions. As studied in detail in [77-79], the electrochemical doping/un-doping processes involve not only the interface electrode-electrolyte, but the entire polymer volume, resulting in conformational and relaxation variations during the electrochemical switching between the reduced (insulating/compact) and oxidised (electronically conducting/relaxed) PPy states. Accordingly, the relaxation time required for the oxidation (doping) of the polymer increases when increasing the time $\left(t_{w}\right)$ of cathodic pre-polarization (un-doping) [80]. By considering a reasonable doping efficiency during the anodic pulses, the portion of un-doped polymer (and thus $t_{w}$ ) gradually increases at every pulse together with the time required to re-dope the polymer. This results in a slight decrease in polymer electronic conductivity with the pulse cycles and, thus, in the effective applied potential $\left(E_{\text {eff }}=1.2 \mathrm{~V}-\eta_{\mathrm{ohm}, \mathrm{PPY}}\left(n_{\text {pulse }}\right)\right)$. A possible contribution to this effect could arise from the incorporation of non-conductive Mn/Co oxy-hydroxides. As demonstrated by previous studies based on micro-X-ray absorption spectroscopy, metallic Co can be also incorporated, but in lower quantity [32], while metallic $\mathrm{Mn}$ is not present $[34,36]$. The increase of $i_{\mathrm{m}}$ values can be related to three factors: (i) the gain of the effective surface area of the electrode due to the appearance of a number of fresh nuclei at every pulse; (ii) a possible increase of the growth rate of the nuclei pre-formed in the previous anodic pulse at higher potential [81]; (iii) the increase of the electropolymerisation kinetics related to the progressive PPy coverage of the electrode surface [32]. The traditional use of $i$ - $t$ curves to extract mechanistic information, is to discriminate between instantaneous and progressive nucleation and assigning numerical values for $N_{s}$ and $A N_{o}$, respectively. These two types of nucleation are in fact limiting cases of a more general situation in which, at any given time, nuclei both form and grow. A simple way of accounting for this is to formulate models able to accommodate with continuity a family of curves intermediate between the two limiting cases. This can be achieved e.g., by decoupling the parameters $A$ and $N_{o}$ and defining an analytical form of the transient in which $A$ can vary over the whole positive real semiaxis (e.g., $[69,82,83])$. The conceptual clarity of this approach, as well as the possibility of estimating $A$ and $N_{o}$ from a single transient, are in practice counteracted by added numerical complexities that in fact end up recoupling the two parameters. A simpler approach was proposed in [84], based on the linear combination of the two limiting cases of instantaneous and progressive nucleation with a weight $W: 0 \leq W \leq 1$ [84]. $W$ gives a measure of the distance from the limiting cases ( $W=0$ progressive nucleation, $W=1$ instantaneous nucleation) and provides a single-parameter, physically straightforward description of the shape changes of $i-t$ transients. The only other free parameter $t_{\mathrm{m}}$ can be interpreted simply by referring to both (weighted) limiting nucleation cases. Moreover, it can be straightforwardly proved that the weighted equation can be regarded as an approximation of the $i-t$ curves proposed in the references quoted above in this section. Accordingly, the current density and time of the experimental current transients have been normalised according to the coordinates of current maximum: $\left(i_{\mathrm{m}}, t_{\mathrm{m}}\right)$ and compared to the theoretical $i / i_{\mathrm{m}}$ vs. $t / t_{\mathrm{m}}$ curves [84] in Figure 2C. The values of $W$ have been determined through an iterative fitting process according to the protocol reported in [85] and plotted as a function of the number of pulses in Figure 2D. The results show that the instantaneous and progressive mechanisms equally contribute to the nucleation process during the application of the pulse train. 


\subsubsection{Cathodic Potensiostatic Pulse}

Figure 3A shows the experimental cathodic chronoamperograms observed during the pulsed step potentiostatic synthesis of the Mn-Co/PPy samples at the applied cathodic potential of $-1.8 \mathrm{~V}$. As for the anodic pulse, the shape of the transients shows a rapid increase in current up to a maximum, followed by a current drop characteristic of cathodic nucleation and growth of a solid material on a conducting surface. The electrodeposited nuclei are made of a composite material, the nature of which is determined by the possible cathodic processes: (i) reduction of the $\mathrm{Mn}$ (II) and $\mathrm{Co}(\mathrm{II})$ complexes in the bath to $\mathrm{Mn}(0)$ and $\mathrm{Co}(0)$; (ii) cathodic reduction of the $\mathrm{Mn}(\mathrm{III}) / \mathrm{Mn}$ (IV) and $\mathrm{Co}$ (II) oxides species already incorporated into PPy; (iii) polymer un-doping and (iv) cathodic electroprecipitation of $\mathrm{Mn}$ and Co oxy-hydroxides. The nucleation of a solid phase on the electrode surface, well-known for the electrodeposition of metals (reaction (i)), has been also observed during the precipitation of oxy-hydroxides under electrogeneration of base (reaction (iv)) [86]. The maximum current density $\left(i_{\mathrm{m}}\right)$ and the corresponding time $\left(t_{\mathrm{m}}\right)$ are plotted as a function of the pulse number as shown in Figure 3B. The slight increase of $t_{\mathrm{m}}$, as discussed for the anodic chronoamperograms, can be related to the gradual increase in the ohmic drop of polymer, resulting in a corresponding lowering of the effective applied cathodic potential. The progressive increase of maximum cathodic current density $\left(i_{\mathrm{m}}\right)$ with the pulse number can be due to the increase of the effective surface area of the electrode due to the cumulative growth of new nuclei and to the roughening of the PPy surface, influenced by the conformational compactness of the polymer during the un-doping process, i.e., perchlorate anion expulsion [79]. The $W$ values have been determined as detailed for in Section 3.1.2.1 and plotted as a function of the number of pulses (Figure 3D). Inspection of $W$ values shows that the nucleation mechanism is mainly progressive and the instantaneous contribution increases with the pulse number until the end of the pulse train where the two contribute equally $(W=\sim 0.5)$.

(A) potentiostatic transients
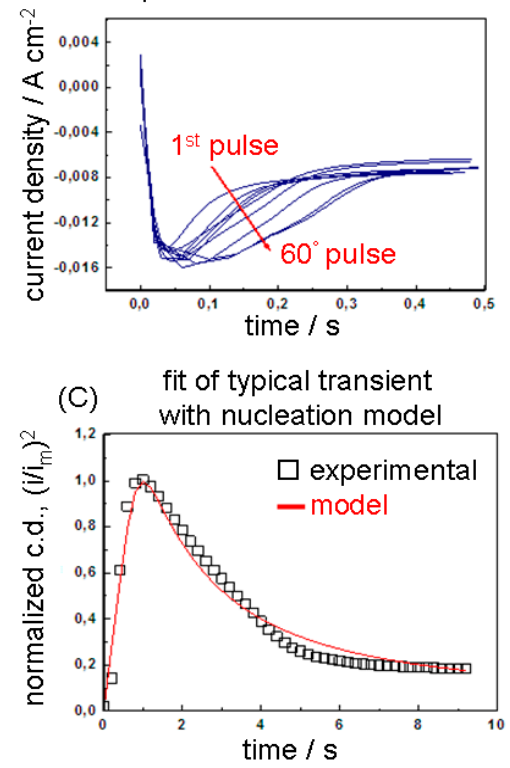

(B)

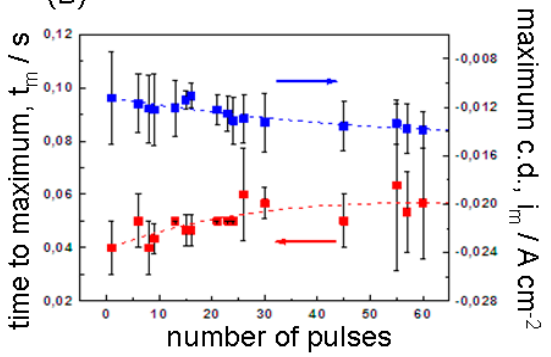

(D)

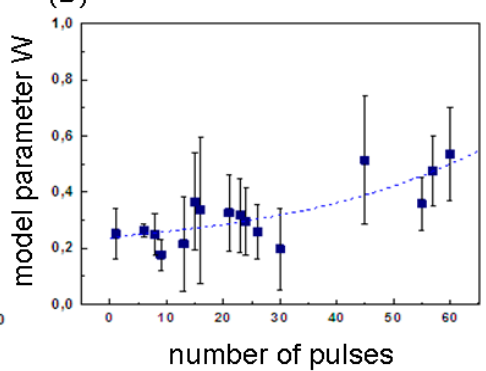

Figure 3. (A) Potentiostatic transients measured during the cathodic growth of Mn-Co/PPy on a graphite electrode in contact with acetonitrile/water $1 \mathrm{vol} \%$ solutions containing $0.1 \mathrm{M} \mathrm{TBAP}, 0.1 \mathrm{M}$ pyrrole, $0.025 \mathrm{M} \mathrm{MnCl}_{2}$ and $0.025 \mathrm{M} \mathrm{CoCl}_{2}$ at the applied potential of $-1.8 \mathrm{~V}(\mathrm{Ag} / \mathrm{AgCl})$; (B) Maximum current density $\left(i_{\mathrm{m}}\right)$ and the corresponding time $\left(t_{\mathrm{m}}\right)$ as a function of the number of the sequential pulses recorded during the electrosynthesis; (C) Dimensionless plot of a typical chronoamperogram (the 45th one), compared with the theoretical mixed nucleation curve [Mele 09]; (D) $W$ values obtained by best fitting of each cathodic chronoamperogram. The $i_{\mathrm{m}}, t_{\mathrm{m}}$ and $W$ values reported on the Panels $(\mathrm{B}, \mathrm{D})$ are averaged (the error bar is the standard deviation) on four independent experimental data sets. 
Of course, the simultaneous presence of instantaneous and progressive nucleation processes and their relative weight during pulse plating could be fully understood by only taking into account the complex interplay of electrochemical, chemical and polymerisation processes. In fact, the nucleation mechanism is strongly dependent on the nature of the growing material as well as on the features of the substrate and on the properties of the electrolyte. As discussed above, different electrochemical processes operate simultaneously during the same anodic and cathodic nucleation processes. Furthermore, the chemical nature of $\mathrm{Mn}-\mathrm{Co} / \mathrm{PPy}$ nuclei and the prevailing electrodeposition kinetics change with the pulse number due to the variability of the electrocatalytic properties of the electrode surface depending on the Mn-Co species already deposited, with possible activation of concurrent reactions such as $\mathrm{H}_{2}$ evolution as well as on the electrical and conformational properties of the PPy, resulting in changes of porosity and electrical field distribution.

The dynamic interplay of complex chemical conditions expounded above calls for a multitechnique approach, sensitive to the space distribution of the valence of the elements involved in view of a comprehensive understanding of the relevant electrodeposition process.

\subsection{Oxygen Reduction Reaction (ORR) Electrocatalytic Performance}

The electrocatalytic activity towards ORR of as-electrodeposited Mn-Co/PPy samples was investigated following the protocol described in Section 2.1 Figure 4A reports the ORR LSV curves of Mn-Co/PPy, compared to those corresponding to the Mn/PPy composite electrodeposited under otherwise identical conditions and to the bare GC support. Of course, the presence of M/PPy $(\mathrm{M}=\mathrm{Mn}$ and/or Co) on GC drastically improves the ORR electrocatalysis with respect to bare GC in terms of: (i) onset potential ( $\left.E_{\text {onset }}\right)$; (ii) half wave potential $\left(E_{1 / 2}\right)$ and (iii) nominal current density. The ORR curves recorded on GC typically exhibit two waves (I and II in Panel A) both attributed to the 2-electron transfer reduction of $\mathrm{O}_{2}$ producing $\mathrm{H}_{2} \mathrm{O}_{2}$ [87]. The values of onset potentials are quite similar for Mn-Co/PPy $\left(E_{\text {onset }}=-0.115 \mathrm{~V}\right), \mathrm{Mn} / \mathrm{PPy}\left(E_{\text {onset }}=-0.085 \mathrm{~V}\right)$ and $\mathrm{Co} / \mathrm{PPy}$ $\left(E_{\text {onset }}=-0.1 \mathrm{~V}[32]\right)$ and close to the value of $-0.09 \mathrm{~V}$ recorded for polycrystalline bulk $\mathrm{Pt}$ in the same conditions [32]. The beneficial effect of Co addition to Mn/PPy on the ORR can be observed from the half wave potential increase from $E_{1 / 2}=-0.364 \mathrm{~V}(\mathrm{Mn} / \mathrm{PPy})$ to $-0.280 \mathrm{~V}(\mathrm{Mn}-\mathrm{Co} / \mathrm{PPy})$, the latter appearing negatively shifted by $110 \mathrm{mV}$ with respect to the bulk Pt data measured in a previous work of ours $\left(E_{1 / 2}=-0.17 \mathrm{~V}\right)$ [32].

In Figure 4B, we report ORR quasi-steady-state voltammograms of as-electrodeposited $\mathrm{Mn}-\mathrm{Co} / \mathrm{PPy}$ samples at a scan rate of $5 \mathrm{mV} \cdot \mathrm{s}^{-1}$ in $\mathrm{O}_{2}$-saturated $0.1 \mathrm{KOH}$ aqueous solutions at different $\mathrm{RDE}$ rotation speeds. The presence of a non-perfectly flat plateau in the high-current density region of these cyclovoltammetric curves is often observed in M/N/C electrocatalytic materials [31,88-91] and has been treated theoretically. This phenomenon can be associated with the heterogeneity of the surface, impeding the attainment of pure diffusion-limited conditions due to the presence of a distribution of catalytic activity on the surface. The formation of a multiplicity of catalytically active sites can be followed by in situ microspectroscopy measurements, as detailed in Section 3.3.

(A)

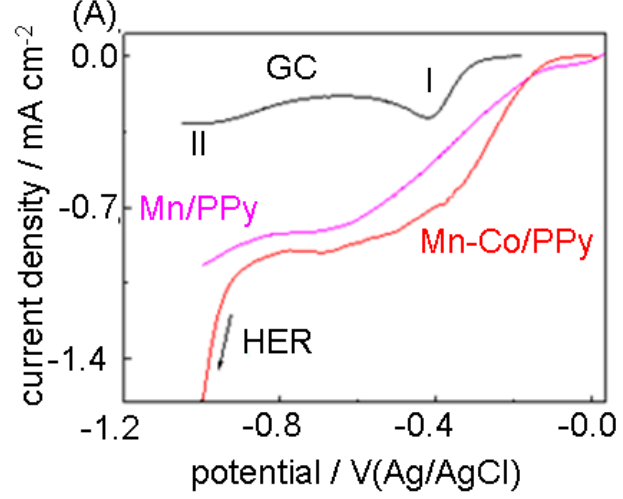

(B)

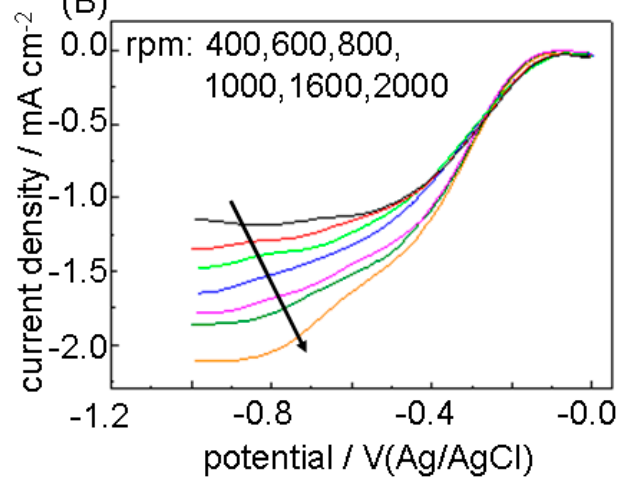

Figure 4. Cont. 
(C)

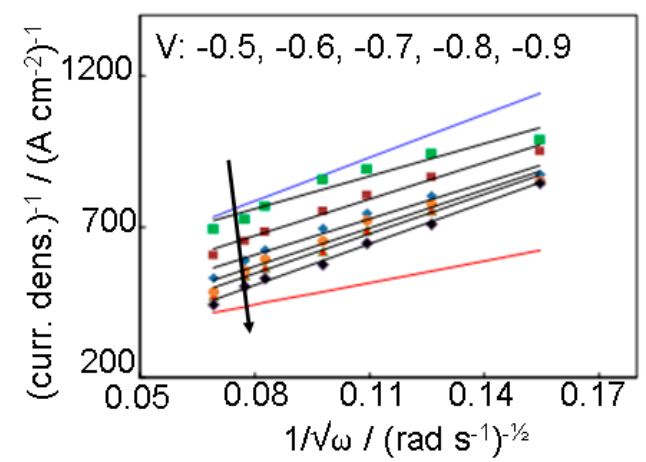

(D)

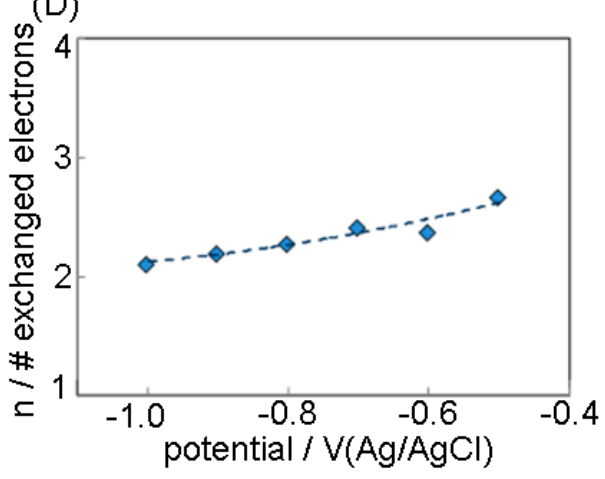

Figure 4. (A) LSVs curves recorded at Mn/PPy/GC, Mn-Co/PPy/GC and GC electrode in $0.1 \mathrm{M}$ $\mathrm{O}_{2}$-saturated $0.1 \mathrm{KOH}$ solution at $5 \mathrm{mV} \cdot \mathrm{s}^{-1} ;$ (B) Rotating Disk Electrode (RDE) voltammograms (scan rate: $5 \mathrm{mV} \cdot \mathrm{s}^{-1}$ ) of $\mathrm{Mn}$-Co/PPy electrodeposited on $\mathrm{GC}$ in $\mathrm{O}_{2}$-saturated $0.1 \mathrm{M} \mathrm{KOH}$ at different rotation rates. The $\mathrm{N}_{2}$ background has been subtracted; (C) Koutecky-Levich plots derived from the curves of Panel (C) at a series of representative potentials; (D) Dependence of the electron transfer number $n$ on the electrode potential for Mn-Co/PPy samples.

The electron transfer number $n$ was determined by the Koutecky-Levich equations [92]:

$$
\begin{gathered}
\frac{1}{j}=\frac{1}{j_{L}}+\frac{1}{j_{K}}=\frac{1}{B \sqrt{\omega}}+\frac{1}{j_{K}} \\
B=0.62 n F C_{\mathrm{o}}\left(D_{\mathrm{o}}\right)^{\frac{2}{3}} v^{-\frac{1}{6}}
\end{gathered}
$$

where: $j_{K}$ is the kinetic current density; $j_{L}$ the diffusion-limiting current density; $j$ the measured current density; $B$ the reciprocal of the slope; $\varpi$ the angular velocity of the disk; $F$ the Faraday constant, $C_{0}$ the saturation concentration of $\mathrm{O}_{2}$ in $0.1 \mathrm{M} \mathrm{KOH}$ at room temperature $\left(1.2 \times 10^{-6} \mathrm{~mol} \cdot \mathrm{cm}^{-3}\right)$; $D_{0}$ the diffusion coefficient of oxygen in water $\left(1.73 \times 10^{-5} \mathrm{~cm}^{2} \cdot \mathrm{s}^{-1}\right)$ and $v$ the kinematic viscosity of the solution at room temperature $\left(0.01 \mathrm{~cm}^{2} \cdot \mathrm{s}^{-1}\right)$ [93]. The Koutecky-Levich plots are reported in Figure $4 \mathrm{C}$. The slopes of their linear fit lines were used to estimate $n$ according to Equation (2) in a range of electrode potentials that are representative of practical electrocatalytic operation. The $n$ values, averaged in the potential range $-0.5--1 \mathrm{~V}$, were found to be $2.35 \pm 0.197$, suggesting the prevalence of ORR two-electron mechanism on the four-electron reduction to water. Similar values are reported for $\mathrm{Mn}_{3} \mathrm{O}_{4} / \mathrm{C}(n=2.4), \mathrm{MnO} / \mathrm{C}(n=2.2)$ and $\mathrm{MnO}_{2} / \mathrm{C}(n=2.3)$ in the same potential range [94]. As shown in Figure 4D, higher $n$ values are found in the low overpotential range: a similar behaviour has been reported for $\mathrm{MnO}_{\mathrm{x}} / \mathrm{C}$ electrocatalysts [94], where the Koutecky-Levich electron number $n$ approaches 2 at high overpotentials and higher rotation rates and 4 at low overpotentials (at ca. $0.106 \mathrm{~V}$ ) and low rotation rates. Since as-electrodeposited PPy is ORR inactive [31], the knowledge of the chemical-state of $\mathrm{Mn}$ and $\mathrm{Co}$ in the composite and its correlation with the electrodeposition parameters is key to optimising the synthesis process toward more efficient electrocatalysts.

\subsection{In Situ X-ray Fluorescence (XRF) Mapping and Scanning X-ray Absorption Microscopy (SXM)}

Elemental and chemical-state distributions during electrodeposition were followed in situ by XRF and SXM, respectively. Chemical-state sensitivity was achieved by acquiring stacks of absorption images by scanning the beam energy across the Co and $\mathrm{Mn} \mathrm{L}_{3}$-edges. XRF and SXM images were collected after having applied appropriate numbers of electrodeposition cycles, highlighting the morphochemical changes taking place between the initial stages of nanocomposite growth and the final condition of an electrocatalyst layer of practical interest (typically between 50 and 120 cycles). 


\subsubsection{Cell Fabrication}

The fabrication process of the liquid cells starts from the production of $100 \mathrm{~nm}$ thick Silicon Nitride $\left(\mathrm{Si}_{3} \mathrm{~N}_{4}\right)$ windows by standard $\mathrm{KOH}$ etching $\left(33 \%\right.$ in weight, $\left.90{ }^{\circ} \mathrm{C}\right)$ (for more details, see [33]). Every cell consists of two silicon chips exhibiting different window patterns. In the first chip, we fabricate three windows, two of which are employed as an inlet and outlet for electrolyte injection. The third one, located in an intermediate position, is manufactured with a novel process (Figure 5A) allowing to obtain a soft X-ray transparent window consisting of a $1 \times 1 \mathrm{~mm}^{2} \mathrm{Si}_{3} \mathrm{~N}_{4}$ membrane surrounded by a $2 \times 2 \mathrm{~mm}^{2} \mathrm{Si}$ frame with a thickness that is locally smaller than that of the wafer $(100$ against $500 \mu \mathrm{m})$. This window geometry allows the collection of signal also at grazing angle (see Panels (7) and (8) of Figure 5A). The electrodes were obtained by a standard lift-off process consisting in a first Proximity ultraviolet (UV) Lithography step (PMGI SF3§1813 resist bilayer was used), thermal evaporation of a $\mathrm{Cr} / \mathrm{Au}$ metal film (thicknesses 5 and $40 \mathrm{~nm}$, respectively) and subsequent stripping of resists in hot acetone and MF319 develop. Of course, any material suitable to be deposited with a lithographic approach can be used in our cell concept and the choice of electrodes is no way limited to Au. The sealed reservoir for electrolyte containment with controlled height was obtained by joining the two silicon chips through a multistep fabrication procedure, consisting in a first step of deposition and patterning of convenient negative resist (SU8-3000.5) by UV lithography on one part to produce the channel of liquid path. The second chip has been put in contact and joined under low pressure with a UV curable resin (NOA 84) in order to ensure the sealing action (Figure 5B). The spacing between the two optical windows, defining the thickness of the electrolyte layer, is $500 \mathrm{~nm}$. After injection of the electrolyte, the inlet and outlet ports are closed by gluing thin glass slide pieces by Araldite adhesive, providing perfect sealing and negligible solvent emission under high vacuum condition.

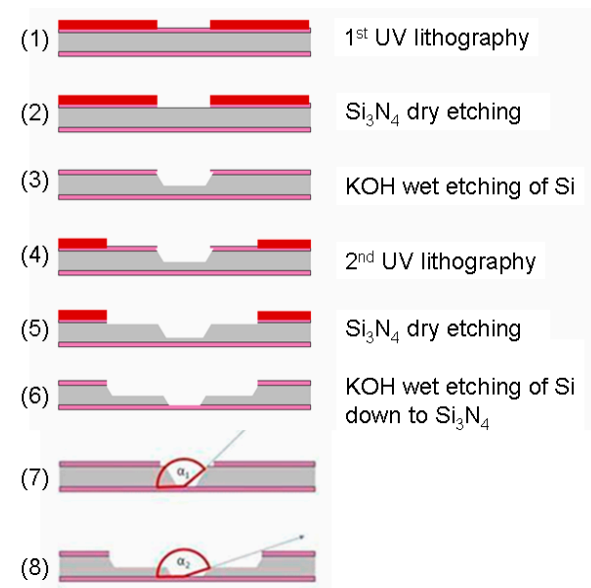

(A)

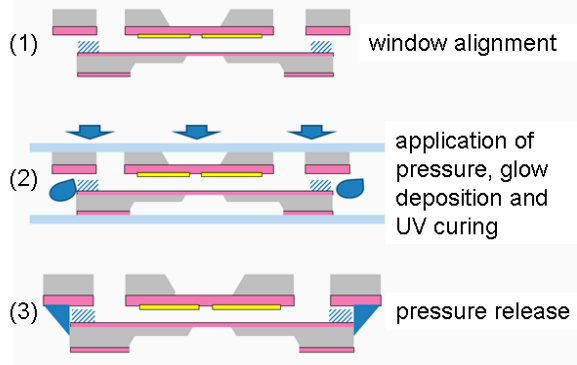

(B)

Figure 5. (A) After the definition of suitable pattern by proximity UV lithography (1), the silicon nitride film has been etched by the reactive ion etching process. A first $\mathrm{KOH}$ step (2) etches a groove in the $\mathrm{Si}$ wafer of dimension close to that of the final $\mathrm{Si}_{3} \mathrm{~N}_{4}$ window. A second lithographic step (3), followed by dry-etching (4), defines the frame pattern. The final $\mathrm{KOH}$ etch (5) produces the $\mathrm{Si}_{3} \mathrm{~N}_{4}$ window supported on a Si frame of controlled thickness (500 nm). Panels (7) and (8) show the difference in signal emission angle of between the conventional narrow window (7) and the novel wide one (8); (B) Cell-assembly scheme. The procedure consists in: (1) alignment of the $\mathrm{Si}_{3} \mathrm{~N}_{4}$ windows; (2) application of a controlled pressure, addition of NOA 84 and cross-linking by UV exposure, after which the final cell configuration (3) is obtained.

\subsubsection{Dynamic XRF Mapping}

In order to assess the progressive build-up of Mn and Co during the growth of Mn-Co/PPy composites, XRF mapping was performed after the application of appropriate sequences of 
electrodeposition steps. Owing to experimental time constraints, only two conditions were compared at high lateral resolution, while several growth steps were monitored at lower resolution. In Figure 6, we report Mn (Panels A and C) and Co (Panels B and D) high-lateral resolution XRF maps measured in situ after 21 (Panels A and B) and 48 cycles (Panels C and D), together with an optical micrograph of the whole electrodic system of the micro-cell showing the location of the analysed zone, alongside with a representative absorption image of the same zone. The accumulation of the two elements with electrodeposition time and their time-dependent distribution can be appreciated. As demonstrated in [33], the current density is higher at the electrode-electrolyte border and it progressively decreases going inside the electrode. A difference in space distribution is found between Co and $\mathrm{Mn}$ that can be explained on the basis of the electrokinetic peculiarities of the two metals. Since the build-up of Co is almost entirely controlled by electroreduction of $\mathrm{Co}(\mathrm{II})$, a higher concentration of Co is found close to the WE border (Panels B and D), following the secondary current density distribution at the electrode-electrolyte interface. Mn instead is chiefly incorporated via basic salt precipitation triggered by electrochemical alkalinisation and the latter element is relatively more homogeneously distributed (panels A and C). In fact, alkalinisation is controlled by a reaction-diffusion process for which the source term is localized at the electrode-electrolyte interface, but precipitation also occurs in the bulk, following the hydroxide concentration gradient.

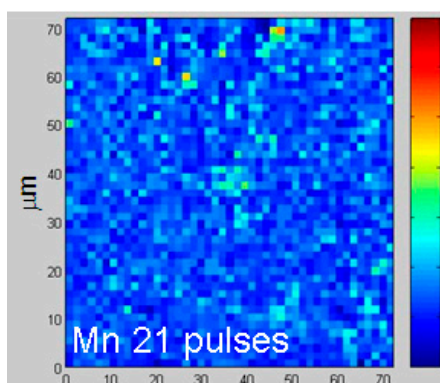

(A)

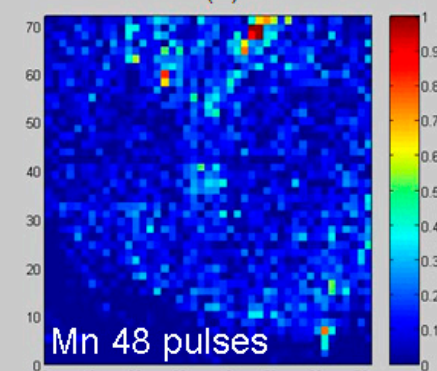

(C)

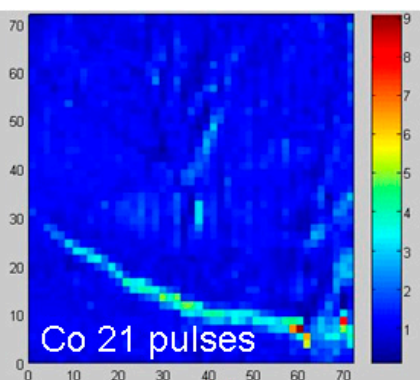

$(\mathrm{B})$

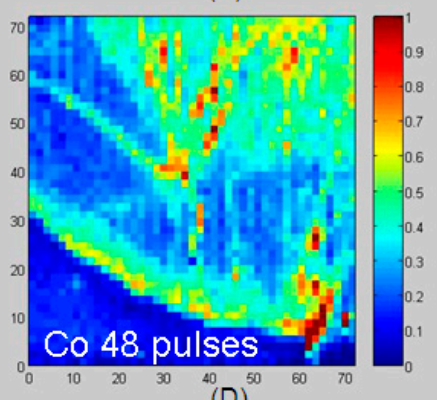

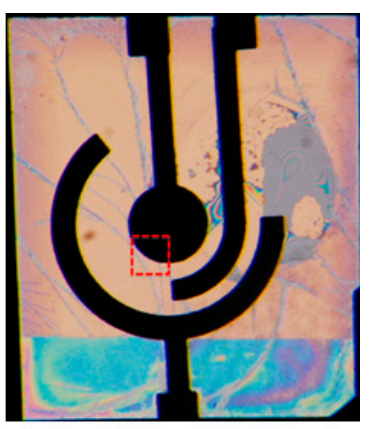

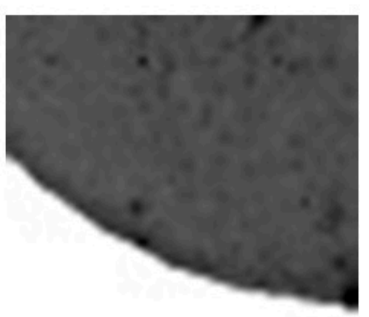

Figure 6. Soft $\mathrm{X}$-ray fluorescence $(\mathrm{XRF}) \mathrm{Mn}(\mathrm{A}, \mathrm{C})$ and $\mathrm{Co}(\mathbf{B}, \mathrm{D})$ high-lateral resolution maps (1.5 $\mu \mathrm{m}$ spot size), elaborated as indicated below. (A,B) Maps measured after 48 growth steps divided by the corresponding maps recorded after 21 growth steps; (C,D) Maps measured after 48 growth steps (normalised). All XRF maps are normalised with respect to the corresponding scattering map. On the right-hand side of the figure, an optical micrograph of the whole electrodic system is shown, with the indication of the analysed zone, alongside with a representative absorption image of the working electrode (acquired at $920 \mathrm{eV}$ after 10 growth steps).

The patterns forming in the internal region of the WE are controlled by reaction-diffusion processes and can be followed with the DIB electrodeposition model (see [95-97] and references therein contained). Non-linear least squares fitting of experimental data with the DIB model has been recently demonstrated and will be the subject of a dedicated publication. The progress of the electrodeposition process can be even more clearly appreciated from Figure 7, which depicts a sequence of XRF Mn and Co maps recorded after 19, 32, 42 and 45 electrodeposition steps. The images reported in Figure 7 are at 
lower space resolution than those shown in Figure 6 and contain the raw data without any smoothing or interpolation: this is physically important, even though it is at the cost of cosmetic appeal, because artefacts can be introduced but such image processing actions alter the physical message. Such lower space resolution is dictated by synchrotron beamtime restrictions-Beyond aesthetics-That does not impair the physical message of the measurement. It is worth noting that also this pattern development can be followed with the DIB model, which is able to predict a morphochemical transient evolving towards steady-state patterns, coherent with the time-behaviour displayed by the succession of panels.

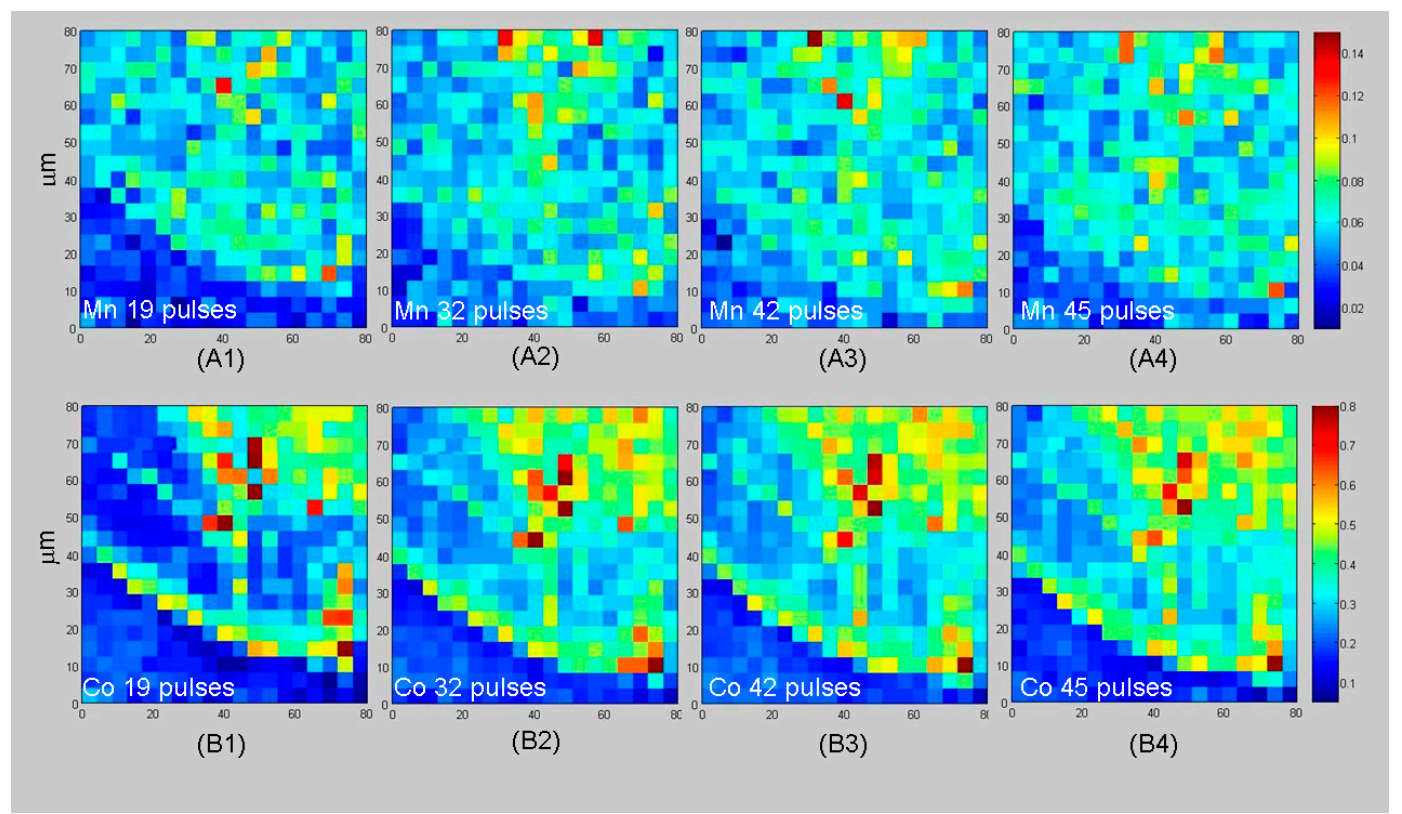

Figure 7. XRF Mn (A1-A4) and Co (B1-B4) low-lateral resolution maps (4.0 $\mu \mathrm{m}$ spot size), elaborated as indicated below. Maps measured after: (1) 19, (2) 32, (3) 42 and (4) 45 growth steps, normalised with respect to the corresponding scattering maps.

\subsubsection{Chemical-State Mapping with Stacks of SXM Absorption Images}

By using the SXM imaging mode, it is possible to extract elemental and chemical-state information at high lateral resolution. According to this approach, conventional SXM images are acquired while scanning the energy across relevant absorption edges: the resulting stack of images encodes absorption contrast changes with the beam energy, which allows to extract an absorption spectrum for each pixel of the micrograph. In this case, we analysed in situ the WE after the growth of a catalyst layer resulting from the application of 120 electrodeposition cycles by scanning the energy across the $\mathrm{Mn}_{2}$ and Co $\mathrm{L}_{3}$-edges in steps of $0.25 \mathrm{eV}$. In Figure 8, we report a selection of representative $\mathrm{Mn}$ and Co spectra extracted from these stacks of images, further analysed in Figures 9 and 10. We investigated the electrode edge (Figure 9) as well as a dendrite that has developed as a result of the rather prolonged growth time (Figure 10). Panels A-D of both figures report a selection of results of the elaboration of the stacks of absorption images, while the other panels provide complementary information. In particular: (i) Panels E and F show a typical SXM image from the stack, corresponding to the $\mathrm{L}_{3}$ absorption edge; (ii) Panels $\mathrm{G}$ and $\mathrm{H}$ report, respectively, high-lateral resolution absorption and phase-contrast images of the same region and (iii) Panels I and J the Mn and Co XRF maps acquired during the measurements of image $(G)$. Of course, the stacks of images contain a large amount of information and can be elaborated in several ways in order to extract compositional and chemical-state maps. As far as the spectral features of the $\mathrm{Co} \mathrm{L}_{3}$ edge XAS are concerned (Figure 8A), it should be noted that whereas $\mathrm{Co}(0)$ is characterized by a single principal feature at ca. $778.7 \mathrm{eV}$ and $\mathrm{Co}(\mathrm{II})$ shows two main peaks at 776.7 and $778.0 \mathrm{eV}, \mathrm{Co}(\mathrm{III})$ exhibits two principal bands at 780.2 and $782.3 \mathrm{eV}$. 
The $\mathrm{Mn} \mathrm{L}_{2}$ XAS spectra (Figure $8 \mathrm{~B}$ ) have distinct features for different Mn oxidation states, some of them being at very close photon energies (Mn(0) ca. $639.3 \mathrm{eV}, \mathrm{Mn}$ (II) ca. $640.5 \mathrm{eV}, \mathrm{Mn}$ (III) ca. $641.7 \mathrm{eV}$, $\mathrm{Mn}(\mathrm{IV})$ ca. $643.5 \mathrm{eV}$ ), so they can overlap in the case of coexistence of several oxidation states. In particular, none of the spectra exhibits the pure line shape of a single Mn oxidation state, but typically consist of two or three overlapping components. Owing to the fact that the spectral features of the $\mathrm{Mn} \mathrm{L}_{2}$ edge systematically shift to higher photon energies with an increased oxidation state, the principal components can be extracted for mapping purposes in a reliable way. In the present study, we concentrated on: (i) elemental distribution (Mn and Co: Panels A and C of Figures 9 and 10) and (ii)-Since the peaks essentially exhibit two components corresponding to the elemental $\mathrm{M}(0)$ and divalent $\mathrm{M}(\mathrm{II})$ forms of the metal, coherent with [33,35]—The ratio $\mathrm{M}(\mathrm{II}) / \mathrm{M}(0), \mathrm{Mn}(\mathrm{II}) / \mathrm{Mn}(0)$ and $\mathrm{Co}(\mathrm{II}) / \mathrm{Co}(0)$ : Panels B and D of Figures 9 and 10). Still more specifically, restricting chemical state, mapping to the $\mathrm{M}(\mathrm{II}) / \mathrm{M}(0)$ ratio does not lead to a loss of information since the trend of the oxidation states with current density is a systematic one, that confirms the findings of $[33,35]$. The elemental distributions were obtained by peak integration and the chemical-state distribution by rationing the intensities of the appropriate peak components over suitable regions of interest. By comparing Panels $\mathrm{A}$ and C of Figures 9 and 10, one can notice that more $\mathrm{Mn}$ than $\mathrm{Co}$ is found in higher current density regions, coherently with the electrodeposition mechanism of each metal, recalled above in Section 3.3.2. Similarly, analysis of Panels B and D shows higher $\mathrm{Mn}(\mathrm{II}) / \mathrm{Mn}(0)$ and $\mathrm{Co}(\mathrm{II}) / \mathrm{Co}(0)$ ratios in higher current density regions, matching with the findings of [33,36], respectively; it is worth emphasising that the results of these papers were based on the collection of a series of local absorption spectra in selected positions of the WE rather than on each pixel of the image as in the present investigation. Regions characterised by differences in local current density exhibit different proportions of elemental and oxidized Co. In particular, from Figures 9 and 10, it is evident that higher current density areas are richer in oxidised Co while lower current density ones are enriched in the elemental form. This is a result of the combined anodic/cathodic electrodeposition process necessary for the formation of the relevant composite. This can be simply explained by the fact that, from the employed solution, Co can only be brought into the solid phase as $\operatorname{Co}(0)$ during the cathodic steps of the potentiostatic sequence, while polypyrrole forms during the anodic steps; during the anodic steps, $\mathrm{Co}$, originally deposited as $\mathrm{Co}(0)$, partially oxidises. During subsequent cathodic steps, in principle, depending on the activity of these species, oxidised Co present in the film can transform back to the metallic state. Thus, in the high-current density areas where the oxidation rate is higher, the formation of $\mathrm{Co}(\mathrm{II})$ is favoured. Furthermore, inspection of the chemlocal state maps shows that, in the high current density areas, Co tends to form well-defined particles, coherent with high growth rate conditions. In these regions, Co can be measured only in the particles, while no Co signal is measured in other locations corresponding to the flat zones of the electrode. In intermediate current density areas, Co appears more uniformly distributed over the electrode. The XAS intensities correlate well with the absorption contrast: the highest intensities found in the intermediate current density region are about the same as those of the hot-spots of the high current density zone. Notably less intense Co spectra, chiefly corresponding to $\mathrm{Co}(0)$, are obtained in the low current density areas. Upon inspection of the distributions of $\mathrm{Mn}$ and $\mathrm{Mn}(\mathrm{II}) / \mathrm{Mn}(0)$ ratios, one can clearly see that differences in current density induce inhomogeneities both in the amount and in the chemical state of electrodeposit. Moving from lower to higher current densities, there is a systematic shift to higher photon energies, indicative of the fact that higher current densities favour the deposition of oxidised forms of $\mathrm{Mn}$, with a predominance of $\mathrm{Mn}$ (II) with respect to $\mathrm{Mn}(0)$. Notwithstanding the fact that $\mathrm{Mn}$ (II) can be formed both by electrochemical oxidation of pre-deposited $\mathrm{Mn}(0)$ and by precipitation of $\mathrm{Mn}$ (II) basic salts (see Section 3.3.2 above) meaning that the distribution of $\mathrm{Mn}(\mathrm{II})$ is more homogeneous, which is the explanation given for Co of the correlation between $\mathrm{M}(\mathrm{II}) / \mathrm{M}(0)$ and current density that also applies to $\mathrm{Mn}$. The steeper current density gradients present on the dendrite illustrated in Figure 10 explain the higher heterogeneity in elemental and chemical-state distributions found in this unstable outgrowth feature with respect to the smoother region analysed in Figure 9. 


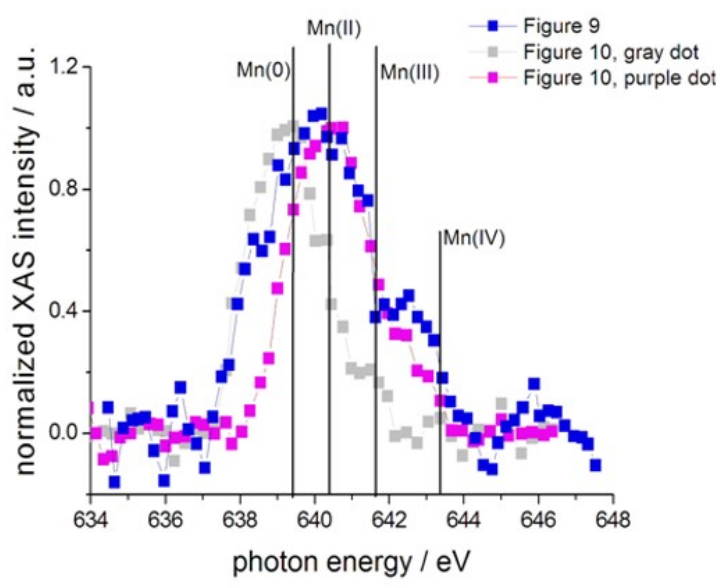

(A)

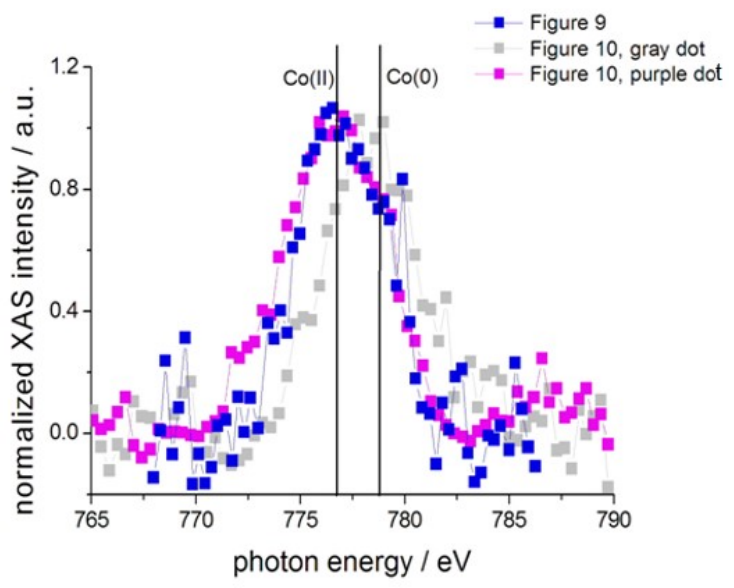

(B)

Figure 8. (A) $\mathrm{Mn}_{2}$ and (B) $\mathrm{Co} \mathrm{L}_{3}$ XAS spectra extracted from stacks of images and corresponding to one pixel. The positions of the relevant pixels are shown in Figures 9 and 10.

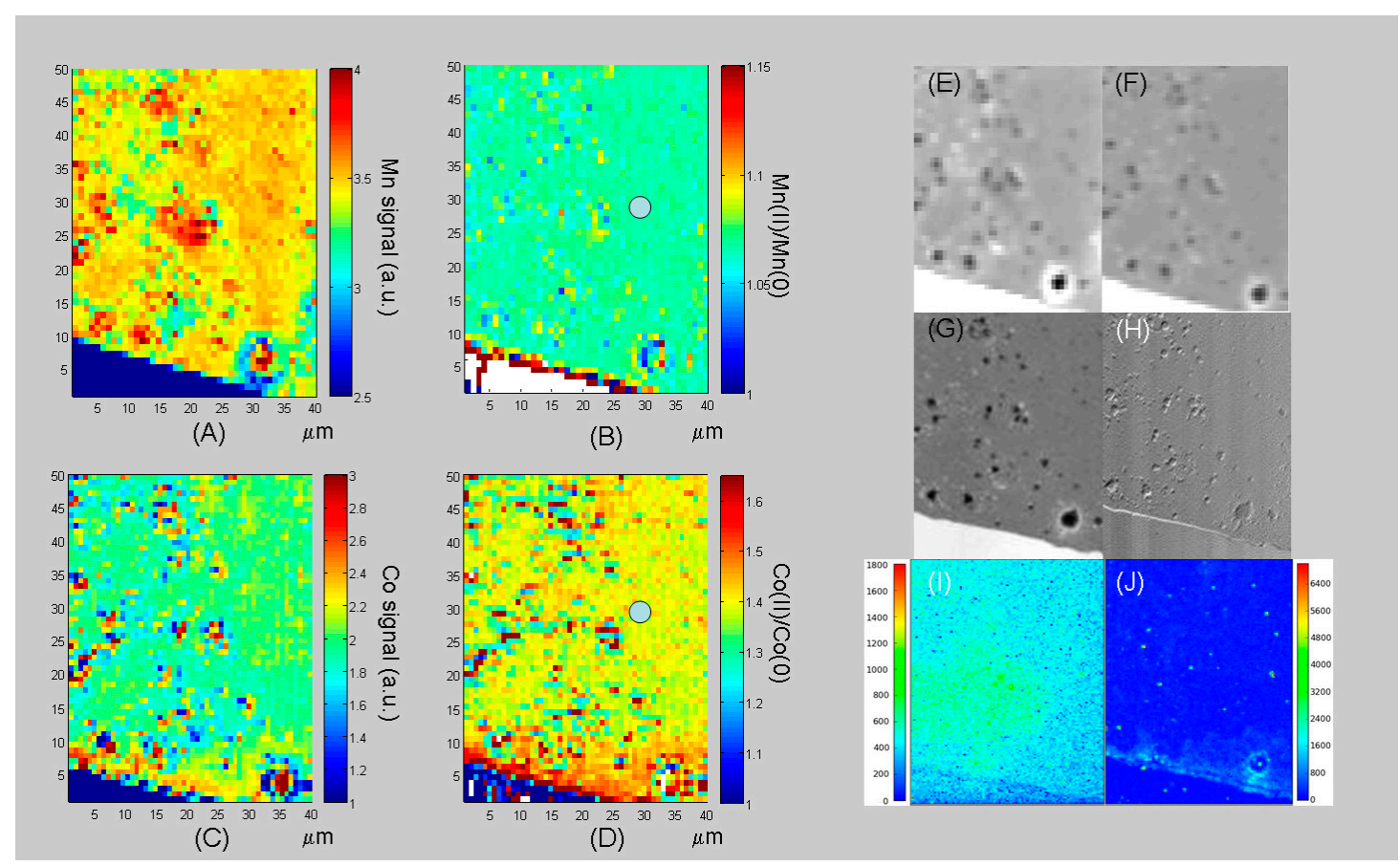

Figure 9. (A-D) Images reconstructed from stacks of SXM images recorded in situ across the Mn $(\mathbf{A}, \mathbf{B})$ and Co (C,D) L $\mathrm{L}_{3}$-edges after 120 electrodeposition cycles. Elemental distributions $(1 \mu \mathrm{m}$ spot size diameter) of $\mathrm{Mn}(\mathbf{A})$ and $\mathrm{Co}(\mathbf{C})$. Mn(II)/Mn(0) (B) and Co(II)/Co(0) (D) ratios; (E,F) Examples of SXM images (1 $\mathrm{mm}$ spot size diameter) extracted from the stack, at the $\mathrm{Mn}$ and $\mathrm{Co} \mathrm{L}_{3}$-edge, respectively; $(\mathbf{G}, \mathbf{H})$ High-lateral resolution (200 $\mathrm{nm}$ spot size diameter) SXM images ((G) absorption contrast, (H) phase contrast: the vertical stripes are due to synchrotron beam instabilities) of the same region, recorded at $920 \mathrm{eV}$ and (I,J) the corresponding high-lateral resolution (200 nm spot size diameter) Mn and Co XRF maps, respectively, acquired at $920 \mathrm{eV}$. The grey dot indicates the position to which the XAS spectra reported in Figure 8 correspond. 


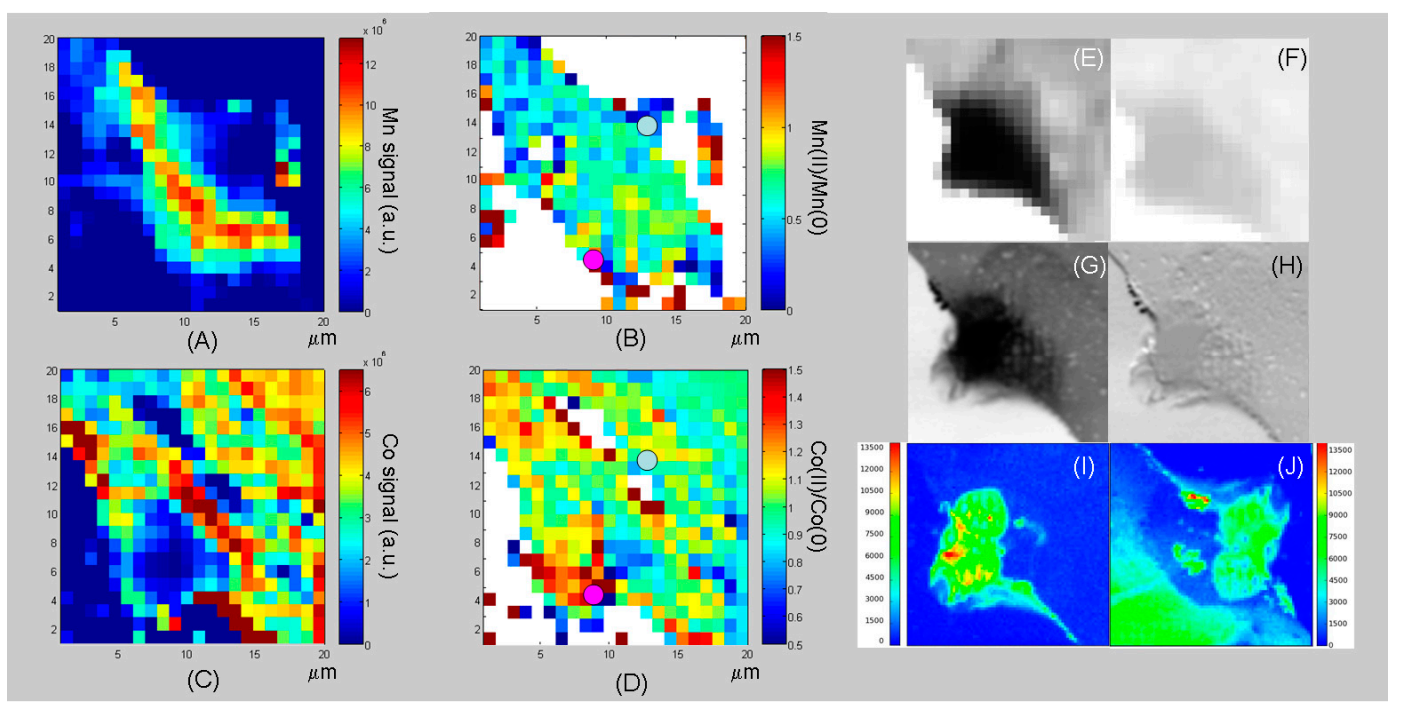

Figure 10. (A-D) Images of a dendrite reconstructed from stacks of SXM images recorded in situ across the $\mathrm{Mn}(\mathbf{A}, \mathbf{B})$ and $\mathrm{Co}(\mathbf{C}, \mathbf{D}) \mathrm{L}_{3}$-edges after 120 electrodeposition cycles. Elemental distributions (1 $\mu \mathrm{m}$ spot size diameter) of $\mathrm{Mn}(\mathbf{A})$ and $\mathrm{Co}(\mathrm{C}) . \mathrm{Mn}(\mathrm{II}) / \mathrm{Mn}(0)(\mathbf{B})$ and $\mathrm{Co}(\mathrm{II}) / \mathrm{Co}(0)$ (D) ratios; (E,F) Examples of SXM images (1 $\mu \mathrm{m}$ spot size diameter) extracted from the stack, at the Mn and Co L-edge, respectively; (G,H) High-lateral resolution (250 nm spot size diameter) SXM images ((G) absorption contrast, $(\mathbf{H})$ phase contrast) of the same region, recorded at $920 \mathrm{eV}$ and $(\mathbf{I}, \mathbf{J})$ the corresponding high-lateral resolution (250 nm spot size diameter) Mn and Co XRF maps, respectively, acquired at $920 \mathrm{eV}$. The grey and purple dots indicate the positions to which the XAS spectra reported in Figure 8 correspond. The grey spot is at the root of the dendrite, while the purple one is at its tip.

\section{Conclusions}

The present research expounds the electrochemical fabrication of $\mathrm{Mn}-\mathrm{Co}_{\mathrm{O}} \mathrm{O}_{\mathrm{x}} /$ polypyrrole nanocomposites for electrocatalytic applications relevant to metal-air battery technology, and contributes to the mechanistic understanding of the pulsed electrodeposition process. Our study is based on a multi-technique approach combining electrochemical measurements and complementary in situ soft-X-ray fluorescence and absorption microspectroscopies, allowing an understanding of time- and space-dependent phenomena leading to nanocomposite formation.

As evidenced by cyclovoltammetric measurements, the anodic electron-transfer processes corresponding to the formation of Mn(III, IV) oxides and Mn-Co mixed oxides as well as the doping of PPy with perchlorate anions occur under the same electrochemical conditions, giving rise to synergistic effects that are not found in the electrochemical synthesis of the individual components of the composite, as well as to a modification in the polymer electronic structure, related to co-doping with perchlorate, $\mathrm{Mn}(\mathrm{II})$ and $\mathrm{Co}(\mathrm{II})$. In particular, high-cathodic processes (formation of $\mathrm{Mn}(\mathrm{II})$ and $\mathrm{Mn}(0)$ as well as base generation) are inhibited by polymer un-doping. Anodic and cathodic potentiostatic transients-Corresponding to the oxidation and reduction branches of the composite synthesis protocol, respectively-Show a progressive decrease in the number of generated nuclei, accompanied by an enhancement of the transient current maximum. The former process is a result of the fact that the rate at which the PPy incorporates anions at every anodic pulse is influenced by the preceding cathodic pulse, that in turn controls the structural compaction driven by anion expulsion; while the latter phenomenon results, on the one hand from surface area growth resulting from progressive nucleation, and on the other hand from the anodic growth-rate enhancement of polymer nuclei generated in foregoing oxidation cycles. The overall transient current behaviour correlates with a slight, but measurable decrease in polymer electronic conductivity with the pulse number. Finally, in the cathodic and anodic pulses, the prevailing nucleation mechanisms were found to be progressive and instantaneous, respectively. As far as the ORR catalytic performance is concerned, the beneficial 
effect of Co can be observed from a notable half wave potential increase with respect to Mn/PPy. Moreover, the electron transfer number $n$ was to be ca. 2.3, corresponding to a prevailing two-electron $\mathrm{O}_{2}$ reduction mechanism.

The build-up of the elemental distribution of Mn and Co during the growth of Mn-Co/PPy composites could be followed by in situ XRF mapping. The space and time distribution of the two electrodeposited elements is coherent with the electrodeposition mechanisms of $\mathrm{Mn}$ and Co in this system (precipitation of the formed, direct reduction of the latter), controlled on the one hand by the current density distribution ensured with electrode design and on the other hand by reaction-diffusion processes that yield spatio-temporal pattern formation. The analysis of stacks of absorption images acquired in situ by scanning the beam energy across the $\mathrm{Mn}$ and $\mathrm{Co}_{3}$-edges was used to image the elemental (Mn and $\mathrm{Co}$ ) and chemical-state $(\mathrm{M}(\mathrm{II}) / \mathrm{M}(0)$ ) distributions prevailing on the one hand in a relatively homogeneous region of the working electrode and on the other end on a dendrite. We found that more $\mathrm{Mn}$ than Co is found in higher current density regions, in line with the findings of our XRF maps. Similarly, higher $\mathrm{Mn}(\mathrm{II}) / \mathrm{Mn}(0)$ and $\mathrm{Co}(\mathrm{II}) / \mathrm{Co}(0)$ ratios were measured in higher current density regions, confirming - Though with a much higher lateral resolution-The observations and mechanistic interpretations proposed in previous works of ours centred on the coelectrodeposition of the individual metals with PPy, based on in situ local XAS.

Acknowledgments: The authors are indebted to Simone Dal Zilio from IOM-CNR (Istituto Officina dei Materiali-Consiglio Nazionale delle Ricerche) (Basovizza-Trieste, Italy) for having fabricated the microcells.

Author Contributions: Benedetto Bozzini designed and coordinated the study. Benedetto Bozzini, George Kourousias and Alessandra Gianoncelli performed the soft X-ray microscopy experiments and corresponding data processing, Patrizia Bocchetta prepared the solutions and performed the electrochemical experiments. George Kourousias and Alessandra Gianoncelli were involved in analyzing the XRF data.

Conflicts of Interest: The authors declare no conflict of interest.

\section{References}

1. Chakkaravarthy, C.; Waheed, A.K.A.; Udupa, H.V.K. Zinc-Air alkaline batteries-A review. J. Power Sources 1981, 6, 203-228. [CrossRef]

2. Mao, L. Mechanistic study of the reduction of oxygen in air electrode with manganese oxides as electrocatalysts. Electrochim. Acta 2003, 48, 1015-1021. [CrossRef]

3. Klápště, B.; Vondrák, J.; Velická, J. $\mathrm{MnO}_{\mathrm{x}} / \mathrm{C}$ composites as electrode materials II. Reduction of oxygen on bifunctional catalysts based on manganese oxides. Electrochim. Acta 2002, 47, 2365-2369. [CrossRef]

4. Vondrák, J.; Klápšte, B.; Velická, J.; Sedlař́́ková, M.; Reiter, J.; Roche, I.; Chainet, E.; Fauvarque, J.F.; Chatenet, M. Carbon/Manganese oxide based fuel cell electrocatalyst using "flywheel" principle. J. New Mater. Electrochem. Syst. 2005, 8, 1-4.

5. Gorlin, Y.; Jaramillo, T.F. A bifunctional nonprecious metal catalyst for oxygen reduction and water oxidation. J. Am. Chem. Soc. 2010, 132, 13612-13614. [CrossRef] [PubMed]

6. Pickrahn, K.L.; Park, S.W.; Gorlin, Y.; Lee, H.-B.-R.; Jaramillo, T.F.; Bent, S.F. Active $\mathrm{MnO}_{\mathrm{x}}$ Electrocatalysts Prepared by Atomic Layer Deposition for Oxygen Evolution and Oxygen Reduction Reactions. Adv. Energy Mater. 2012, 2, 1269-1277. [CrossRef]

7. Ohsaka, T.; Mao, L.; Arihara, K.; Sotomura, T. Bifunctional catalytic activity of manganese oxide toward $\mathrm{O}_{2}$ reduction: Novel insight into the mechanism of alkaline air electrode. Electrochem. Commun. 2004, 6, $273-277$. [CrossRef]

8. Jiao, F.; Frei, H. Nanostructured manganese oxide clusters supported on mesoporous silica as efficient oxygen-evolving catalysts. Chem. Commun. 2010, 46, 2920-2922. [CrossRef] [PubMed]

9. Chang, J.-K.; Lee, M.-T.; Huang, C.-H.; Tsai, W.-T. Physicochemical properties and electrochemical behavior of binary manganese-cobalt oxide electrodes for supercapacitor applications. Mater. Chem. Phys. 2008, 108, 124-131. [CrossRef]

10. Cheng, F.; Su, Y.; Liang, J.; Tao, Z.; Chen, J. $\mathrm{MnO}_{2}$-Based Nanostructures as Catalysts for Electrochemical Oxygen Reduction in Alkaline Media. Chem. Mater. 2010, 22, 898-905. [CrossRef]

11. Bezdička, P.; Grygar, T.; Klápště, B.; Vondrák, J. $\mathrm{MnO}_{\mathrm{x}} / \mathrm{C}$ composites as electrode materials. I. Synthesis, XRD and cyclic voltammetric investigation. Electrochim. Acta 1999, 45, 913-920. [CrossRef] 
12. Mourad, W.E.; Rophael, M.W.; Khalil, L.B. Preparation and characterization of doped manganese dioxides. J. Appl. Electrochem. 1980, 10, 309-313. [CrossRef]

13. Gyenge, E.L.; Drillet, J.-F. The Electrochemical Behavior and Catalytic Activity for Oxygen Reduction of $\mathrm{MnO}_{2} / \mathrm{C}$-Toray Gas Diffusion Electrodes. J. Electrochem. Soc. 2012, 159, F23. [CrossRef]

14. Benhangi, P.H.; Alfantazi, A.; Gyenge, E. Doped $\mathrm{MnO}_{2}$-Based Oxygen Reduction and Evolution Catalysts for Bifunctional Cathodes in Alkaline Electrochemical Power Sources. In Proceedings of the 224th ECS Meeting, San Francisco, CA, USA, 27 October-1 November 2013; p. 292.

15. Roche, I.; Chaînet, E.; Chatenet, M.; Vondrák, J. Durability of carbon-supported manganese oxide nanoparticles for the oxygen reduction reaction (ORR) in alkaline medium. J. Appl. Electrochem. 2008, 38, 1195-1201. [CrossRef]

16. Roche, I.; Scott, K. Carbon-supported manganese oxide nanoparticles as electrocatalysts for oxygen reduction reaction (ORR) in neutral solution. J. Appl. Electrochem. 2009, 39, 197-204. [CrossRef]

17. Vondrák, J.; Klápšte, B.; Velická, J.; Sedlaříková, M.; Reiter, J.; Roche, I.; Chainet, E.; Fauvarque, J.F.; Chatenet, M. Electrochemical Activity of Manganese Oxide/Carbon-based Electrocatalysts. J. New Mater. Electrochem. Syst. 2005, 8, 209-212.

18. Garfias Garcia, E.; Romero-Romo, M.; Ramírez-Silva, M.T.; Morales, J.; Palomar-Pardavé, M. Eletrochemical Nucleation of Polypyrrole onto Different Substrates. Int. J. Electrochem. Sci. 2010, 5, 763-773.

19. Restovic, A.; Ríos, E.; Barbato, S.; Ortiz, J.; Gautier, J.L. Oxygen reduction in alkaline medium at thin $\mathrm{Mn}_{\mathrm{x}} \mathrm{Co}_{3-\mathrm{x}} \mathrm{O} 4(0 \leq \mathrm{x} \leq 1)$ spinel films prepared by spray pyrolysis. Effect of oxide cation composition on the reaction kinetics. J. Electroanal. Chem. 2002, 522, 141-151. [CrossRef]

20. Hamdani, M.; Singh, R.N.; Chartier, P. $\mathrm{Co}_{3} \mathrm{O}_{4}$ and Co-Based Spinel Oxides Bifunctional Oxygen Electrodes. Int. J. Electrochem. Sci. 2010, 5, 556-577.

21. Du, G.; Liu, X.; Zong, Y.; Hor, T.S.A.; Yu, A.; Liu, Z. $\mathrm{Co}_{3} \mathrm{O}_{4}$ nanoparticle-modified $\mathrm{MnO}_{2}$ nanotube bifunctional oxygen cathode catalysts for rechargeable zinc-air batteries. Nanoscale 2013, 5, 4657-4661. [CrossRef] [PubMed]

22. Wang, Y.; Ma, X.; Lu, L.; He, Y.; Qi, X.; Deng, Y. Carbon supported $\mathrm{MnO}_{\mathrm{x}}-\mathrm{Co}_{3} \mathrm{O}_{4}$ as cathode catalyst for oxygen reduction reaction in alkaline media. Int. J. Hydrog. Energy 2013, 38, 13611-13616. [CrossRef]

23. Bocchetta, P.; Alemán, B.; Amati, M.; Fanetti, M.; Goldoni, A.; Gregoratti, L.; Kiskinova, M.; Mele, C.; Sezen, H.; Bozzini, B. ORR stability of $\mathrm{Mn}-\mathrm{Co} /$ polypyrrole nanocomposite electrocatalysts studied by quasi in-situ identical-location photoelectron microspectroscopy. Electrochem. Commun. 2016, 69, 50-54. [CrossRef]

24. Nguyen Cong, H.; El Abbassi, K.; Gautier, J.L.; Chartier, P. Oxygen reduction on oxide/polypyrrole composite electrodes: Effect of doping anions. Electrochim. Acta 2005, 50, 1369-1376. [CrossRef]

25. Deronzier, A.; Moutet, J.-C. Polypyrrole films containing metal complexes: Syntheses and applications. Coord. Chem. Rev. 1996, 147, 339-371. [CrossRef]

26. Simon, E.; Sablé, E.; Handel, H.; L'Her, M. Electrodes modified by conducting polymers bearing redox sites: $\mathrm{Ni}$ - and Co-cyclam complexes on polypyrrole. Electrochim. Acta 1999, 45, 855-863. [CrossRef]

27. An, K.H.; Jeon, K.K.; Heo, J.K.; Lim, S.C.; Bae, D.J.; Lee, Y.H. High-Capacitance Supercapacitor Using a Nanocomposite Electrode of Single-Walled Carbon Nanotube and Polypyrrole. J. Electrochem. Soc. 2002, 149, A1058. [CrossRef]

28. Sadki, S.; Schottland, P.; Brodie, N.; Sabouraud, G. The mechanisms of pyrrole electropolymerization. Chem. Soc. Rev. 2000, 29, 283-293.

29. Cong, H.N.; Abbassi, K.E.; Chartier, P. Electrocatalysis of Oxygen Reduction on Polypyrrole/Mixed Valence Spinel Oxide Nanoparticles. J. Electrochem. Soc. 2002, 149, A525. [CrossRef]

30. Khilari, S.; Pandit, S.; Das, D.; Pradhan, D. Manganese cobaltite/polypyrrole nanocomposite-based air-cathode for sustainable power generation in the single-chambered microbial fuel cells. Biosens. Bioelectron. 2014, 54, 534-540. [CrossRef] [PubMed]

31. Masa, J.; Schilling, T.; Bron, M.; Schuhmann, W. Electrochemical synthesis of metal-polypyrrole composites and their activation for electrocatalytic reduction of oxygen by thermal treatment. Electrochim. Acta 2012, 60, 410-418. [CrossRef]

32. Bocchetta, P.; Gianoncelli, A.; Abyaneh, M.K.; Kiskinova, M.; Amati, M.; Gregoratti, L.; Jezeršek, D.; Mele, C.; Bozzini, B. Electrosynthesis of Co/PPy nanocomposites for ORR electrocatalysis: A study based on quasi-in situ X-ray absorption, fluorescence and in situ Raman spectroscopy. Electrochim. Acta 2014, 137, 535-545. [CrossRef] 
33. Bozzini, B.; Gianoncelli, A.; Bocchetta, P.; Dal Zilio, S.; Kourousias, G. Fabrication of a Sealed Electrochemical Microcell for In Situ Soft X-ray Microspectroscopy and Testing with In Situ Co-Polypyrrole Composite Electrodeposition for Pt-Free Oxygen Electrocatalysis. Anal. Chem. 2014, 86, 664-670. [CrossRef] [PubMed]

34. Bocchetta, P.; Amati, M.; Gregoratti, L.; Kiskinova, M.; Sezen, H.; Taurino, A.; Bozzini, B. Morphochemical evolution during ageing of pyrolysed $\mathrm{Mn}$ / polypyrrole nanocomposite oxygen reduction electrocatalysts: A study based on quasi-in situ photoelectron spectromicroscopy. J. Electroanal. Chem. 2015, 758, 191-200. [CrossRef]

35. Bozzini, B.; Bocchetta, P.; Alemán, B.; Amati, M.; Gianoncelli, A.; Gregoratti, L.; Sezen, H.; Taurino, A.; Kiskinova, M. Electrodeposition and pyrolysis of Mn/polypyrrole nanocomposites: A study based on soft X-ray absorption, fluorescence and photoelectron microspectroscopies. J. Mater. Chem. A 2015, 3, 19155-19167. [CrossRef]

36. Bozzini, B.; Bocchetta, P.; Gianoncelli, A.; Mele, C.; Kiskinova, M. Electrodeposition and Ageing of Mn-Based Binary Composite Oxygen Reduction Reaction Electrocatalysts. ChemElectroChem 2015, 2, 1541-1550. [CrossRef]

37. Bozzini, B.; Bocchetta, P.; Gianoncelli, A.; Mele, C.; Kiskinova, M. Electrodeposition of Co/CoO nanoparticles onto graphene for ORR electrocatalysis: A study based on micro-X-ray absorption spectroscopy and X-ray fluorescence mapping. Acta Chim. Slov. 2014, 61, 263-271. [PubMed]

38. Kaulich, B.; Bacescu, D.; Susini, J.; David, C.; Di Fabrizio, E.; Morrison, G.R.; Charalambous, P.; Thieme, J.; Wilhein, T.; Kovac, J.; et al. A European Twin X-ray Microscopy Station Commissioned at ELETTRA. Conf. Proc. Ser. IPAP 2006, 7, 22-25.

39. Kaulich, B.; Thibault, P.; Gianoncelli, A.; Kiskinova, M. Transmission and emission X-ray microscopy: Operation modes, contrast mechanisms and applications. J. Phys. Condens. Matter Inst. Phys. J. 2011, 23, 083002. [CrossRef] [PubMed]

40. Gianoncelli, A.; Morrison, G.R.; Kaulich, B.; Bacescu, D.; Kovac, J. Scanning transmission X-ray microscopy with a configurable detector. Appl. Phys. Lett. 2006, 89, 251117. [CrossRef]

41. Morrison, G.R.; Gianoncelli, A.; Kaulich, B.; Bacescu, D.; Kovac, J. A Fast-readout CCD System for Configured-Detector Imaging in STXM. Conf. Proc. Ser. IPAP 2006, 7, 377-379.

42. Gianoncelli, A.; Kaulich, B.; Alberti, R.; Klatka, T.; Longoni, A.; De Marco, A.; Marcello, A.; Kiskinova, M. Simultaneous soft X-ray transmission and emission microscopy. Nucl. Instrum. Methods Phys. Res. Sect. A Accel. Spectrom. Detect. Assoc. Equip. 2009, 608, 195-198. [CrossRef]

43. Gianoncelli, A.; Kourousias, G.; Stolfa, A.; Kaulich, B. Recent developments at the TwinMic beamline at ELETTRA: An 8 SDD detector setup for low energy X-ray Fluorescence. J. Phys. Conf. Ser. 2013, 425, 182001. [CrossRef]

44. Sole, A.; Papillon, E.; Cotte, M.; Walter, P.; Susini, J. A multiplatform code for the analysis of energy-dispersive X-ray fluorescence spectra. Spectrochim. Acta Part B At. Spectrosc. 2007, 62, 63-68. [CrossRef]

45. Heinze, J. Electronically conducting polymers. In Electrochemistry IV; Topics in Current Chemistry; Steckhan, P.D.E., Ed.; Springer: Berlin/Heidelberg, Germany, 1990; pp. 1-47.

46. Trinidad, F.; Alonso-Lopez, J.; Nebot, M. Electrochemical behaviour of polypyrrole films as secondary battery electrodes in $\mathrm{LiClO}_{4}$-propylene carbonate. J. Appl. Electrochem. 1987, 17, 215-218. [CrossRef]

47. Zhou, M.; Heinze, J. Electropolymerization of pyrrole and electrochemical study of polypyrrole: 1 . Evidence for structural diversity of polypyrrole. Electrochim. Acta 1999, 44, 1733-1748. [CrossRef]

48. Liu, P.; Yao, C.; Zhang, W.; Yang, Q.; Li, G.; Tong, Y.; Hope, G.A. Electrochemical preparation of Fe-Mn alloy film in organic bath. Thin Solid Films 2008, 516, 3935-3939. [CrossRef]

49. Pourbaix, M. Atlas of Electrochemical Equilibria in Aqueous Solutions; National Association of Corrosion Engineers: Houston, TX, USA, 1974.

50. Radhakrishnamurthy, P.; Reddy, A.K.N. The mechanism of manganese electrodeposition. J. Appl. Electrochem. 1974, 4, 317-321. [CrossRef]

51. Kolthoff, I.M.; Coetzee, J.F. Polarography in Acetonitrile. II. Metal Ions Which Have Significantly Different Polarographic Properties in Acetonitrile and in Water. Anodic Waves. Voltammetry at Rotated Platinum Electrode. J. Am. Chem. Soc. 1957, 79, 1852-1858. [CrossRef]

52. Elving, P.J.; Spritzer, M.S. Polarografic reduction of hydrogen ion in non-aqueous solvents. Talanta 1965, 12, 1243-1258. [CrossRef] 
53. Wei, W.; Chen, W.; Ivey, D.G. Defective Rock-Salt Structure in Anodically Electrodeposited Mn-Co-O Nanocrystals. J. Phys. Chem. C 2007, 111, 10398-10403. [CrossRef]

54. Morrison, M.M.; Sawyer, D.T. Redox chemistry of the polyimine complexes of manganese(II), -(III), and -(IV) in acetonitrile. Inorg. Chem. 1978, 17, 333-337. [CrossRef]

55. Inzelt, G.; Pineri, M.; Schultze, J.; Vorotyntsev, M. Electron and proton conducting polymers: Recent developments and prospects. Electrochim. Acta 2000, 45, 2403-2421. [CrossRef]

56. Malinauskas, A. Electrocatalysis at conducting polymers. Synth. Met. 1999, 107, 75-83. [CrossRef]

57. Deronzier, A.; Moutet, J.C. Functionalized polypyrroles. New molecular materials for electrocatalysis and related applications. Acc. Chem. Res. 1989, 22, 249-255. [CrossRef]

58. Ikeda, O.; Okabayashi, K.; Tamura, H. Electrocatalytic Reduction of Oxygen on Cobalt-Doped Polypyrrole Films. Chem. Lett. 1983, 12, 1821-1824. [CrossRef]

59. Hepel, M. The Electrocatalytic Oxidation of Methanol at Finely Dispersed Platinum Nanoparticles in Polypyrrole Films. J. Electrochem. Soc. 1998, 145, 124. [CrossRef]

60. Espinoza-Ramos, L.I.; Ramírez, C.; Hallen-López, J.M.; Arce, E.; Palomar-Pardavé, M.; Romero-Romo, M. Electrochemical Study of Passive Layer Formation on Lead-Base Alloys Immersed in $5.31 \mathrm{MH}_{2} \mathrm{SO}_{4}$ Solution. J. Electrochem. Soc. 2002, 149, B543. [CrossRef]

61. Mendoza-Huizar, L.; Robles, J.; Palomar-Pardavé, M. Nucleation and growth of cobalt onto different substrates: Part I. Underpotential deposition onto a gold electrode. J. Electroanal. Chem. 2002, 521, 95-106. [CrossRef]

62. Mendoza-Huizar, L.H.; Robles, J.; Palomar-Pardavé, M. Nucleation and growth of cobalt onto different substrates: Part II. The upd-opd transition onto a gold electrode. J. Electroanal. Chem. 2003, 545, 39-45. [CrossRef]

63. Palomar-Pardavé, M.; González, I.; Batina, N. New Insights into Evaluation of Kinetic Parameters for Potentiostatic Metal Deposition with Underpotential and Overpotential Deposition Processes. J. Phys. Chem. B 2000, 104, 3545-3555. [CrossRef]

64. Martínez-Ruíz, A.; Palomar-Pardavé, M.; Valenzuela-Benavides, J.; Farías, M.H.; Batina, N. Kinetics of Cu Underpotential Deposition on Iodine-Modified Au(111) Electrodes. J. Phys. Chem. B 2003, 107, 11660-11665. [CrossRef]

65. Hölzle, M.H.; Retter, U.; Kolb, D.M. The kinetics of structural changes in Cu adlayers on Au(111). J. Electroanal. Chem. 1994, 371, 101-109. [CrossRef]

66. Palomar-Pardavé, M.; Miranda-Hernández, M.; González, I.; Batina, N. Detailed characterization of potentiostatic current transients with 2D-2D and 2D-3D nucleation transitions. Surf. Sci. 1998, 399, 80-95. [CrossRef]

67. Scharifker, B.; Hills, G. Electrochemical kinetics at microscopically small electrodes. J. Electroanal. Chem. Interfacial Electrochem. 1981, 130, 81-97. [CrossRef]

68. Scharifker, B.; Hills, G. Theoretical and experimental studies of multiple nucleation. Electrochim. Acta 1983, 28, 879-889. [CrossRef]

69. Scharifker, B.R.; Mostany, J. Three-dimensional nucleation with diffusion controlled growth: Part I. Number density of active sites and nucleation rates per site. J. Electroanal. Chem. Interfacial Electrochem. 1984, 177, 13-23. [CrossRef]

70. Hills, G.J.; Schiffrin, D.J.; Thompson, J. Electrochemical nucleation from molten salts-I. Diffusion controlled electrodeposition of silver from alkali molten nitrates. Electrochim. Acta 1974, 19, 657-670. [CrossRef]

71. Gòmez, E.; Ramirez, J.; Vallès, E. Electrodeposition of Co-Ni alloys. J. Appl. Electrochem. 1988, $28,71$. [CrossRef]

72. Abyaneh, M.Y. General Models for Surface Nucleation and Three-Dimensional Growth: The Effects of Concurrent Redox Reactions and of Diffusion. J. Electrochem. Soc. 1991, 138, 2491. [CrossRef]

73. Garfias-García, E.; Romero-Romo, M.; Ramírez-Silva, M.T.; Morales, J.; Palomar-Pardavé, M. Mechanism and kinetics of the electrochemical formation of polypyrrole under forced convection conditions. J. Electroanal. Chem. 2008, 613, 67-79. [CrossRef]

74. Hwang, B.J.; Santhanam, R.; Lin, Y.-L. Nucleation and Growth Mechanism of Electropolymerization of Polypyrrole on Gold/Highly Oriented Pyrolytic Graphite Electrode. J. Electrochem. Soc. 2000, 147, 2252. [CrossRef] 
75. Hwang, B.-J.; Santhanam, R.; Lin, Y.-L. Evaluation of Structure, Nucleation and Growth Mechanism of Electropolymerized Polypyrrole on Highly Oriented Pyrolytic Graphite Electrode. Electroanalysis 2003, 15, 115-120. [CrossRef]

76. Huynh, M.; Bediako, D.K.; Liu, Y.; Nocera, D.G. Nucleation and Growth Mechanisms of an Electrodeposited Manganese Oxide Oxygen Evolution Catalyst. J. Phys. Chem. C 2014, 118, 17142-17152. [CrossRef]

77. Otero, T.F.; Boyano, I. Comparative Study of Conducting Polymers by the ESCR Model. J. Phys. Chem. B 2003, 107, 6730-6738. [CrossRef]

78. Otero, T.F.; Grande, H.; Rodríguez, J. Conformational relaxation during polypyrrole oxidation: From experiment to theory. Electrochim. Acta 1996, 41, 1863-1869. [CrossRef]

79. Otero, T.F.; Padilla, J. Anodic shrinking and compaction of polypyrrole blend: Electrochemical reduction under conformational relaxation kinetic control. J. Electroanal. Chem. 2004, 561, 167-171. [CrossRef]

80. Otero, T.F.; Grande, H.-J.; Rodríguez, J. Reinterpretation of Polypyrrole Electrochemistry after Consideration of Conformational Relaxation Processes. J. Phys. Chem. B 1997, 101, 3688-3697. [CrossRef]

81. Handbook of Semiconductor Electrodeposition. Available online: https://www.crcpress.com/Handbookof-Semiconductor-Electrodeposition/Pandey/p/book/9780824797010 (accessed on 29 June 2016).

82. Mostany, J.; Mozota, J.; Scharifker, B.R. Three-dimensional nucleation with diffusion controlled growth: Part II. The nucleation of lead on vitreous carbon. J. Electroanal. Chem. Interfacial Electrochem. 1984, 177, $25-37$. [CrossRef]

83. Tsakova, V.; Milchev, A. Comparative studies of electrochemical phase formation by amperometric and microscopic methods: Part I. Nucleation kinetics in dilute solutions of mercury nitrate. J. Electroanal. Chem. Interfacial Electrochem. 1987, 235, 237-247. [CrossRef]

84. Mele, C.; Rondinini, S.; D’Urzo, L.; Romanello, V.; Tondo, E.; Minguzzi, A.; Vertova, A.; Bozzini, B. Silver electrodeposition from water-acetonitrile mixed solvents and mixed electrolytes in the presence of tetrabutylammonium perchlorate. Part I-Electrochemical nucleation on glassy carbon electrode. J. Solid State Electrochem. 2009, 13, 1577-1584. [CrossRef]

85. Kemmer, G.; Keller, S. Nonlinear least-squares data fitting in Excel spreadsheets. Nat. Protoc. 2010, 5, $267-281$. [CrossRef] [PubMed]

86. Eliaz, N.; Eliyahu, M. Electrochemical processes of nucleation and growth of hydroxyapatite on titanium supported by real-time electrochemical atomic force microscopy. J. Biomed. Mater. Res. A 2007, 80A, 621-634. [CrossRef] [PubMed]

87. Yeager, E. Dioxygen electrocatalysis: Mechanisms in relation to catalyst structure. J. Mol. Catal. 1986, 38, 5-25. [CrossRef]

88. Gojković, S.L.; Gupta, S.; Savinell, R. Heat-treated iron(III) tetramethoxyphenyl porphyrin chloride supported on high-area carbon as an electrocatalyst for oxygen reduction. J. Electroanal. Chem. 1999, 462, 63-72. [CrossRef]

89. Tamizhmani, G.; Dodelet, J.; Guay, D.; Lalande, G.; Capuano, G.A. Electrocatalytic Activity of Nafion-Impregnated Pyrolyzed Cobalt Phthalocyanine a Correlative Study between Rotating Disk and Solid Polymer Electrolyte Fuel-Cell Electrodes. Electrochem. Soc. 1994, 141, 41-45. [CrossRef]

90. Hu, F.-P.; Zhang, X.-G.; Xiao, F.; Zhang, J.-L. Oxygen reduction on Ag- $\mathrm{MnO}_{2} / \mathrm{SWNT}$ and Ag-MnO $/ \mathrm{AB}$ electrodes. Carbon 2005, 43, 2931-2936. [CrossRef]

91. Lalande, G.; Faubert, G.; Côté, R.; Guay, D.; Dodelet, G.P.; Weng, L.T.; Bertrand, P. Catalytic activity and stability of heat-treated iron phthalocyanines for the electroreduction of oxygen in polymer electrolyte fuel cells. J. Power Sources 1996, 61, 227-237. [CrossRef]

92. Bard, A.J.; Faulkner, L.R. Electrochemical Methods: Fundamentals and Applications, 2nd ed.; Wiley: New York, NY, USA, 1980; Available online: http:/ / eu.wiley.com/WileyCDA/WileyTitle/productCd-0471043729.html (accessed on 29 June 2016).

93. Davis, R.E.; Horvath, G.L.; Tobias, C.W. The solubility and diffusion coefficient of oxygen in potassium hydroxide solutions. Electrochim. Acta 1967, 12, 287-297. [CrossRef]

94. Lima, F.H.B.; Calegaro, M.L.; Ticianelli, E.A. Investigations of the catalytic properties of manganese oxides for the oxygen reduction reaction in alkaline media. J. Electroanal. Chem. 2006, 590, 152-160. [CrossRef]

95. Bozzini, B.; Lacitignola, D.; Sgura, I. Spatio-temporal organization in alloy electrodeposition: A morphochemical mathematical model and its experimental validation. J. Solid State Electrochem. 2013, 17, 467-479. [CrossRef] 
96. Gianoncelli, A.; Sgura, I.; Bocchetta, P.; Lacitignola, D.; Bozzini, B. High-lateral resolution X-ray fluorescence microspectroscopy and dynamic mathematical modelling as tools for the study of electrodeposited electrocatalysts. X-ray Spectrom. 2015, 44, 263-275. [CrossRef]

97. Lacitignola, D.; Bozzini, B.; Sgura, I. Spatio-Temporal Organization in a Morphochemical Electrodeposition Model: Analysis and Numerical Simulation of Spiral Waves. Acta Appl. Math. 2014, 132, 377-389. [CrossRef]

(C) 2017 by the authors; licensee MDPI, Basel, Switzerland. This article is an open access article distributed under the terms and conditions of the Creative Commons Attribution (CC-BY) license (http://creativecommons.org/licenses/by/4.0/). 